\title{
Neuroinvasion and Inflammation in Viral Central Nervous System Infections
}

\author{
Tobias Dahm, Henriette Rudolph, Christian Schwerk, \\ Horst Schroten, and Tobias Tenenbaum
}

Pediatric Infectious Diseases, Department of Pediatrics, Medical Faculty Mannheim, Heidelberg University, 68167 Mannheim, Germany

Correspondence should be addressed to Tobias Tenenbaum; tobias.tenenbaum@medma.uni-heidelberg.de

Received 17 December 2015; Revised 16 March 2016; Accepted 12 April 2016

Academic Editor: Mukesh Kumar

Copyright (c) 2016 Tobias Dahm et al. This is an open access article distributed under the Creative Commons Attribution License, which permits unrestricted use, distribution, and reproduction in any medium, provided the original work is properly cited.

Neurotropic viruses can cause devastating central nervous system (CNS) infections, especially in young children and the elderly. The blood-brain barrier (BBB) and the blood-cerebrospinal fluid barrier (BCSFB) have been described as relevant sites of entry for specific viruses as well as for leukocytes, which are recruited during the proinflammatory response in the course of CNS infection. In this review, we illustrate examples of established brain barrier models, in which the specific reaction patterns of different viral families can be analyzed. Furthermore, we highlight the pathogen specific array of cytokines and chemokines involved in immunological responses in viral CNS infections. We discuss in detail the link between specific cytokines and chemokines and leukocyte migration profiles. The thorough understanding of the complex and interrelated inflammatory mechanisms as well as identifying universal mediators promoting CNS inflammation is essential for the development of new diagnostic and treatment strategies.

\section{Introduction}

Viral central nervous system (CNS) infections can be classified depending on the anatomical site of the inflammation and the entry site of viral pathogens. An infection of the meninges is referred to as meningitis, of the brain as encephalitis, and of the spinal cord as myelitis. When a combination of regions is affected, the terms meningoencephalitis or encephalomyelitis are applied [1]. Viral CNS infections are almost threefold as frequent as bacterial infections with an incidence of 20-30/100.000 per year [2,3]. Despite an often mild acute phase, fatal outcomes are possible, while the long term impact of viral CNS infections has not been elucidated in detail yet [4].

In healthy individuals various immune cells, which enhance the protection against invading pathogens, are found in small numbers in the CNS. The majority (70-80\%) of these immune cells in the cerebrospinal fluid (CSF) are phenotypic $\mathrm{CD}^{+}$memory T-cells; both $\mathrm{CD}^{+}$and $\mathrm{CD}^{+}$subsets are present with around $40-50 \%$ and $20-30 \%$, respectively [5]. In contrast, B-cells (dominantly CD $27^{+}$memory cells), natural killer (NK) cells, dendritic cells (DCs), and perivascular and meningeal mast cells as well as monocytes and polymorphonuclear granulocytes (PMN) are only present in low numbers [6-8]. However, the composition of inflammatory cells in the CNS and especially in the CSF, which can be clinically monitored by lumbar puncture, undergoes constant changes throughout a CNS infection.

An increase in the number of leukocytes within the CSF can especially be noted in patients with viral meningitis, whereas during encephalitis, patients rarely exhibit elevated cell counts in the CSF. During encephalitis, immune cells migrate into the brain parenchyma [9]. The cascade of events following viral CNS infection includes the recruitment of Tlymphocytes, macrophages, and to some extent PMN. An increase in $\mathrm{CD}^{+}{ }^{+} \mathrm{T}$-cells, $\mathrm{CD} 8^{+} \mathrm{T}$-cells, and $\mathrm{NK}$ cells has been recorded in the context of viral meningitis. The dominant PMN population seen in early stages of the enteroviral CNS infection, for example, may pave the way for monocytes and lymphocytes [10].

In this review we highlight the role and probable causes of leukocyte migration via the $\mathrm{BBB}$ and the $\mathrm{BCSFB}$ into the CNS 


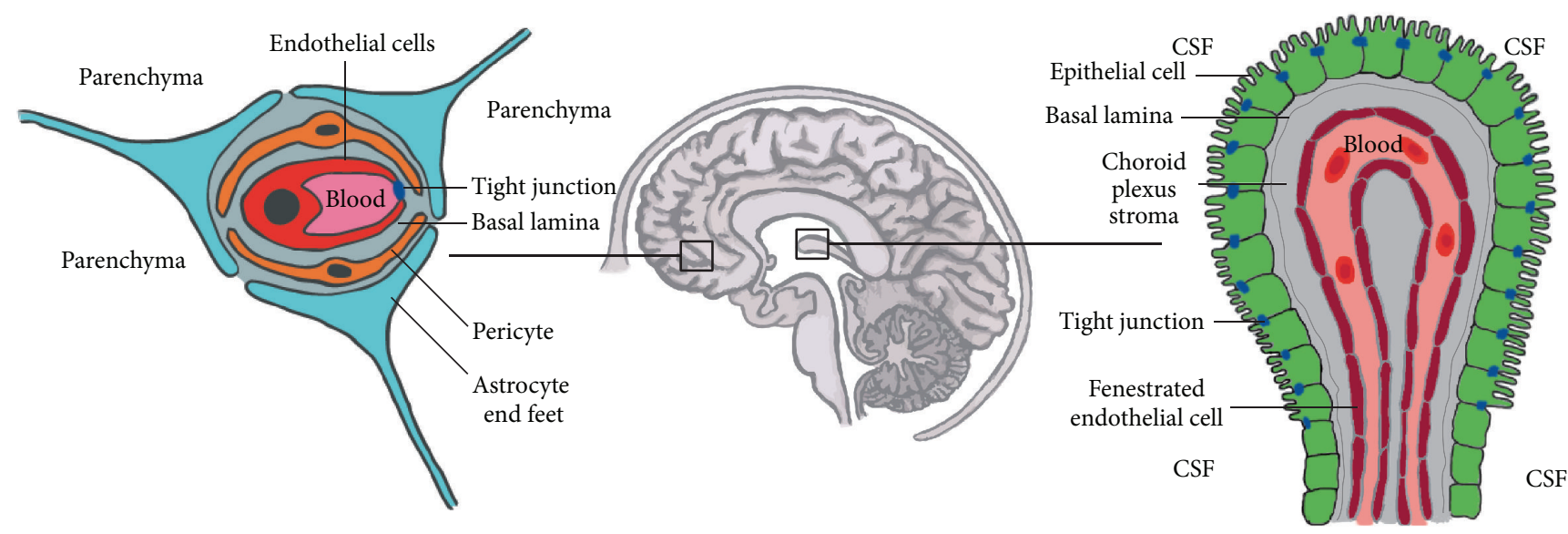

(a)

(b)

FIGURE 1: Barriers of the brain. (a) The BBB found between the lumen of the cerebral blood vessels and the brain parenchyma is composed of capillary endothelial cells, astrocytes, and pericytes and obtains its characteristic physical barrier function via linking the endothelial cells through luminal tight junctions. (b) The BCSFB located between the CSF and the fenestrated blood vessels of the choroid plexus. This selective barrier contains polar choroid plexus epithelial cells joined to one another through tight junctions found on the apical side.

following viral infection. In this context we further describe the associated mediators and their influence on the migration patterns.

\section{Involvement of the Brain Barriers in CNS Infection}

To cause CNS infections pathogens must first successfully cross the protective barriers of the brain. The CNS is an immune-specialized site, which maintains a homogenous environment by regulation of entrance and exit of substances through the major brain barriers: the blood-brain barrier (BBB) and the blood-cerebrospinal fluid barrier (BCSFB) [11]. The BBB and BCSFB form metabolic (enzymatic activity on passing molecules), physical (minimizing the paracellular flux), and transport (controlling molecular flux through specialized membrane transporters) barriers [12, 13] (Figure 1).

The BBB, which has the largest surface area available for communication between the brain and the blood, creates a barrier through a functional unit consisting of endothelial cells, which are joined and stabilized through tight junctions (TJs), astrocyte end feet, and pericytes. This highly selective barrier between the peripheral blood and the brain parenchyma of the CNS consists of specialized cells which in cooperation create a homeostatic environment for cells of the CNS [14, 15] (Figure 2).

The BCSFB is found in the choroid plexus (CP) located in the ventricles of the brain. The epithelium of the CP is mainly responsible for the barrier function of the BCSFB. Apart from maintaining the physical barrier of the $\mathrm{CP}$, the BCSFB, with its array of specific transport channels and a low pinocytotic activity, is involved in para- and transcellular transport of molecules and immune cells between the brain and the cerebrospinal fluid [16]. The endothelial cells within the choroid plexus parenchyma are fenestrated and hardly limit flux of molecules across the endothelial cells [17]. This fenestration is important for the main function of the $\mathrm{CP}$, which is the synthesis of CSF [18].

The paracellular permeability of the BBB and the BCSFB is mainly regulated by two junctional complexes: TJs and adherens junctions (AJs) [19]. The TJs are built and reinforced through a number of junctional proteins such as occludin, claudins, coxsackie adenovirus receptor (CAR), and also junctional adhesion molecules (JAMs), whereas the AJs largely consist of transmembrane cadherins closely linked by alpha, beta, and gamma catenin to the cytoskeleton [19-22]. The primary (direct) or secondary (via host cell signaling events) disruption of those junctional molecules by CNS pathogens can facilitate crossing of virus particles, leukocytes, and inflammatory mediators into the CNS [15].

\section{Pathogen Entry into the CNS}

The brain capillaries and the CP are relevant sites of entry for pathogens such as bacteria, viruses, fungi, and parasites into the CNS. For entry the pathogens must first cross the respective barriers, which are the BBB and the BSCFB. The BBB has been described as an entrance site for bacterial pathogens such as Neisseria meningitidis (N. meningitidis) $[23,24]$ and Streptococcus pneumoniae (S. pneumoniae) [25, 26], for fungi such as Candida albicans (C. albicans) [27, 28], and also for viruses like West Nile virus (WNV) $[29,30]$, human immunodeficiency virus (HIV) [31, 32], or herpes simplex virus (HSV) $[15,33]$. In contrast, the BCSFB has not received the same amount of attention, due to the lack of adequate in vivo and in vitro models for this barrier. To date, a range of bacteria as well as viruses were shown to use the BCSFB as an entry site into the CNS, which include Streptococcus suis (S. suis) [34-36], N. meningitidis [37, 38], Haemophilus influenzae $(H$. influenzae) [39-41], and Listeria monocytogenes [42-44] as well as coxsackievirus B3 (CVB3) $[45,46]$, chikungunya virus (CHIKV) [47], and Echovirus 30 (EV30) [48]. The role of the 


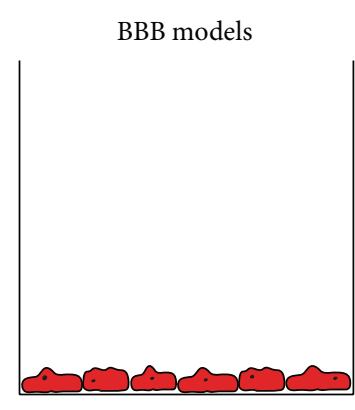

Monoculture

(a)

BBB models

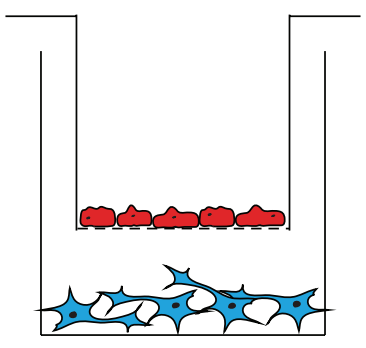

Coculture

(d)
BBB models

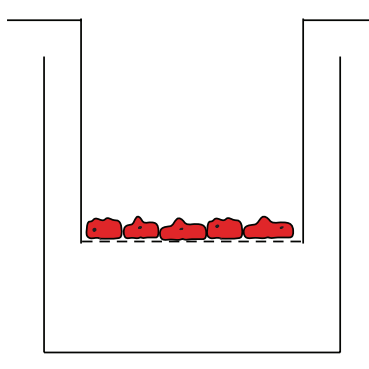

Monoculture

(b)

BBB models

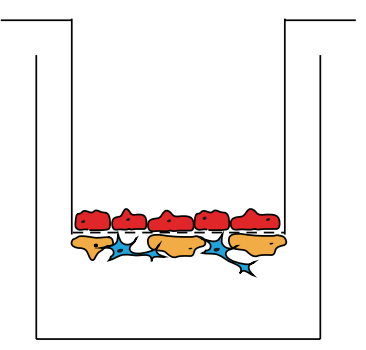

Coculture

(e)
BBB models

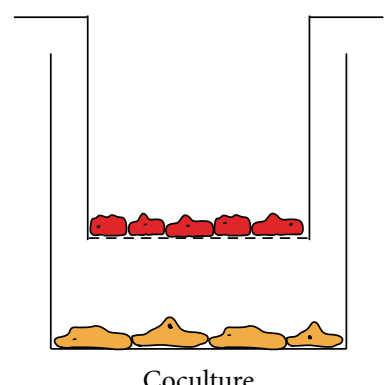

(c)

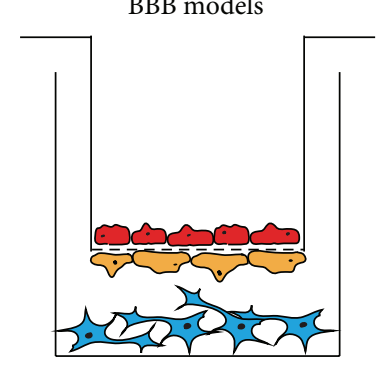

Coculture

(f)

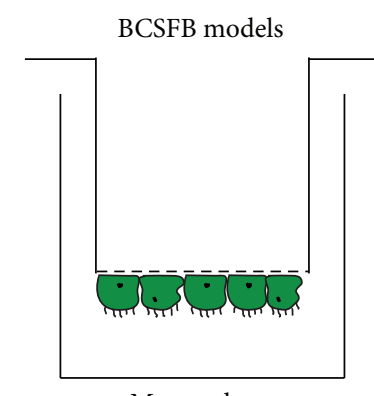

Monoculture

(g)

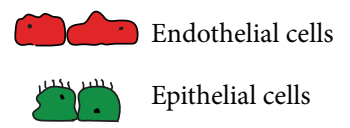

BCSFB models

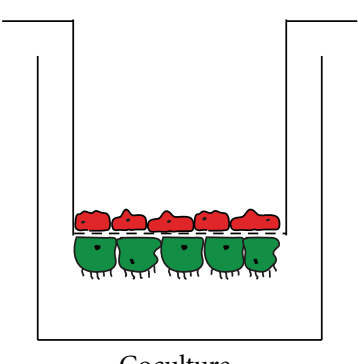

(h)

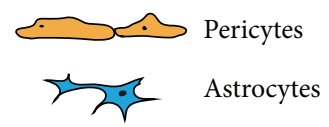

FIGURE 2: Schematic representation of various in vitro BBB and BCSFB models. The BBB models are built up around endothelial cells, whereas the BCSFB models rely on epithelial cell culture. The setup can be a monoculture: endothelial or epithelial cells only (a, b, and g); coculture: endothelial cells with epithelial cells (h) or endothelial cells with pericytes or astrocytes (c and d); and triple-culture: endothelial in combination with astrocytes and pericytes (e and f). These systems can be set up in a "contact" (e, f, and h) or "noncontact" (c and d) manner ("contact": different cell types have physical contact with each other; "noncontact": different cell types were not able to physically interact with each other). The monoculture models represented in (a) and (b) can also be used with epithelial cells instead of endothelial cells. The addition of chemical mediators (cytokines and/or chemokines) and virus or immune cells (T-, B-cells, and PMNs, etc.) is possible in both the filter insert and/or well.

choroid plexus during infectious diseases has previous been reviewed [49]. However, some viruses are better adapted to invade the CNS through peripheral nerves (poliovirus (PV)) [50-52] or olfactory sensory neurons (herpes simplex virus1 (HSV-1)) [53, 54] (Figure 3). Limitation to one of these pathways is not obligatory as can be seen with WNV [55] and PV [56]. The most common pathogens causing viral CNS infection are displayed in Table 1.
Due to the diverse structural characteristics of the brain barriers, pathogens developed a range of different strategies to gain access into the CNS via the host cells. Infectious agents were shown to use the transcellular, paracellular, and the "Trojan horse" approaches [75]. Pathogens migrating transcellularly, such as HSV-1, HIV, and EV 30 , invade directly into host cells to overcome the barrier $[48,76,77]$. For the paracellular transmigration, suggested for HIV-1 [78] and 


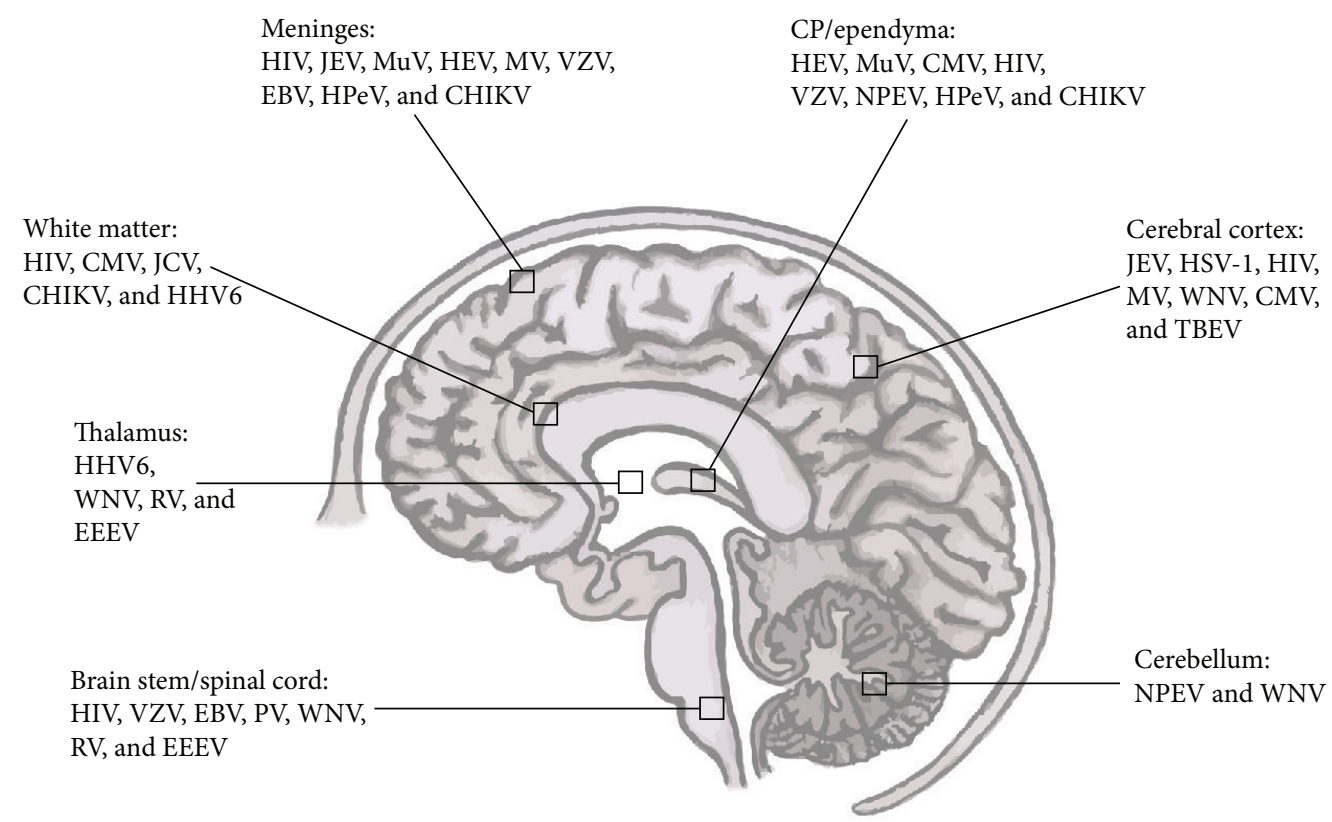

FIGURE 3: Relevant encephalitis and meningitis causing viruses in humans allocated to the brain region they may affect. CHIKV, chikungunya virus; CMV, cytomegalovirus; EBV, Epstein Barr virus; EEEV, eastern equine encephalitis virus; HHV-6, human herpes virus-6; HIV, human immunodeficiency virus; HPeV, human parechovirus; HSV-1, herpes simplex virus-1; JCV, John Cunningham virus; JEV, Japanese encephalitis virus; $\mathrm{MV}$, measles virus; $\mathrm{MuV}$, mumps virus; NPEV, nonpolio enterovirus; PV, poliovirus; RV, rabies virus; TBEV, tick-borne encephalitis virus; WNV, West Nile virus; VZV, varicella zoster virus.

mouse hepatitis virus [79], the pathogens migrate between the TJ molecules. Invasion of pathogens into the CNS whilst internalized in phagocytic host cells has been described as the "Trojan horse" strategy and has been implied to be exploited by many viruses including HIV, CVB3, and WNV [80-83]. However, each pathogen may not use only a single route but rather a combination of strategies [84]. Disruption of the barrier may also lead to increased neuroinvasion and depends on direct cytotoxic effects of the pathogen as well as secondary inflammatory mediators such as cytokines and chemokines, matrix metalloproteinases (MMPs), free radicals, and lipid mediators $[15,85]$.

Successful invasion of pathogens into the CNS via the brain barriers is usually followed by a strong inflammatory host response resulting in a substantial migration of immune cells to the site of infection to control or eradicate the invading pathogens. Host cells at the brain barriers detect pathogenassociated molecular patterns (PAMPs) in the circulating blood, which leads to activation of immune cells found in close proximity [86]. The BCSFB is believed to be the primary site for immune surveillance of the CNS as it acts as a selective gate, whereas the $\mathrm{BBB}$ is designed to function as a strong immunological barrier which hinders leukocyte migration into the parenchyma [87].

\section{Models to Study Viral CNS Infection}

Several in vitro models, both static and under flow conditions, as well as in vivo models, mainly murine, exist to study the pathogenesis of viral CNS infection. Application of in vitro models can facilitate easier handling and may increase the spectrum of potential investigations in comparison to a complex experimental in vivo setup. However, in in vitro setup, it is barely possible to mimic the extremely complex and interrelated structures of the CNS. In vitro models of the $\mathrm{BBB}$ can be grouped into two major set ups: (1) single culture models with brain microvascular endothelial cells (BMEC; primary or immortalized cells) and (2) coculture models with, for example, BMEC, astrocytes, and pericytes and/or glia cells [88, 89] (Figure 2).

A commonly used single culture BBB model to study CNS infection is based on human brain microvascular endothelial cells (HBMEC) [89]. For example, Coyne et al. showed a dynamin and caveolin dependent internalization of PV into HBMEC [90]. Conversely, when repeating similar experiments with non-CNS specific cell lines, such as SH-SY5Y or adherent HeLa (S3), the process showed caveolin independence but a tyrosine kinase dependency [91]. This indicates an organ specific mode of entrance into the CNS. A coculture model with HBMEC in combination with human fetal astrocytes was used to investigate HIV-associated encephalitis [92]. The model showed physiological important characteristics such as a functional monolayer with TJs (resulting in a high electrical resistance) and glial fibrillary acid protein (GFAP) reactivity of the endothelial cells and the astrocytes, respectively [92] (Figure 2).

Viral infiltration and subsequent inflammation of the CNS can also have an effect on the functionality of the BCSFB. Several functional in vitro models of the BCSFB have been developed including primary and immortalized murine cell lines such as Z310 [93, 94], primary and immortalized porcine choroid plexus epithelial cells (PCPEC), and PCP-R 
TABLE 1: Classification, characterization, and affected CNS regions of relevant viruses causing infection in the human CNS.

\begin{tabular}{|c|c|c|c|c|}
\hline Virus family & Species name & Genome structure & Affected CNS regions & $\mathrm{BBB}$ or $\mathrm{BCSFB}$ \\
\hline Retroviridae & $\begin{array}{l}\text { Human immunodeficiency virus } \\
\text { (HIV) [57] }\end{array}$ & $(+)$ ssRNA & $\begin{array}{c}\text { Meninges, cerebral cortex, } \\
\text { white matter, brain stem, } \\
\text { ependyma }\end{array}$ & $\mathrm{BBB}$ \\
\hline \multirow{5}{*}{ Herpesviridae } & Varicella zoster virus (VZV) [58] & dsDNA & $\begin{array}{l}\text { Meninges, brainstem, } \\
\text { subependymal vessels }\end{array}$ & $\mathrm{BBB}$ \\
\hline & Cytomegalovirus (CMV) [59] & dsDNA & $\begin{array}{l}\text { Cerebral cortex, white } \\
\text { matter, ependyma, CP }\end{array}$ & $\mathrm{BBB} / \mathrm{BCSFB}$ \\
\hline & Human herpes virus-6 (HH-6) [60] & dsDNA & $\begin{array}{l}\text { Front lobe, thalamus, white } \\
\text { matter }\end{array}$ & $\mathrm{BBB}$ \\
\hline & Herpes simplex virus-1 (HSV-1) [61] & dsDNA & Cerebral cortex & $\mathrm{BBB}$ \\
\hline & Epstein Barr virus (EBV) [62] & dsDNA & $\begin{array}{l}\text { Meninges, spinal cord, } \\
\text { peripheral nerves }\end{array}$ & $\mathrm{BBB}$ \\
\hline \multirow{3}{*}{ Picornaviridae } & Nonpolio enterovirus (NPEV) [63] & $(+)$ ssRNA & $\mathrm{CP}$, cerebellum & $\mathrm{BBB} / \mathrm{BCSFB}$ \\
\hline & Poliovirus (PV) [64] & $(+)$ ssRNA & Brain stem & $\mathrm{BBB}$ \\
\hline & Human parechovirus (HPeV) [65] & $(+)$ ssRNA & Meninges, ependyma, CP & $\mathrm{BBB} / \mathrm{BCSFB}$ \\
\hline \multirow{3}{*}{ Flaviviridae } & $\begin{array}{l}\text { Tick-borne encephalitis virus (TBEV) } \\
\text { [66] }\end{array}$ & $(+)$ ssRNA & Cerebral cortex & $\mathrm{BBB}$ \\
\hline & West Nile virus (WNV) [67] & $(+) s s R N A$ & $\begin{array}{l}\text { Cerebral cortex, thalamus, } \\
\text { hippocampus, brain stem, } \\
\text { cerebellum }\end{array}$ & $\mathrm{BBB}$ \\
\hline & Japanese encephalitis virus (JEV) [68] & $(+)$ ssRNA & Meninges, cerebral cortex & $\mathrm{BBB}$ \\
\hline \multirow{2}{*}{ Paramyxoviridae } & Measles virus (MV) [69] & $(-)$ ssRNA & Meninges, cerebral cortex & $\mathrm{BBB}$ \\
\hline & Mumps virus $(\mathrm{MuV})[70]$ & $(-)$ ssRNA & Meninges, ependyma, CP & $\mathrm{BBB} / \mathrm{BCSFB}$ \\
\hline Rhabdoviridae & Rabies virus (RV) [71] & $(-)$ ssRNA & $\begin{array}{l}\text { Thalamus, hippocampus, } \\
\text { brain stem }\end{array}$ & BBB \\
\hline Polyomaviridae & John Cunningham virus (JCV) [72] & dsDNA & Subcortical white matter & $\mathrm{BBB}$ \\
\hline \multirow[b]{2}{*}{ Togaviridae } & Chikungunya virus (CHIKV) [73] & $(+) s s R N A$ & White matter, $\mathrm{CP}$, meninges & $\mathrm{BBB} / \mathrm{BCSFB}$ \\
\hline & $\begin{array}{l}\text { Eastern equine encephalitis virus } \\
\text { (EEEV) }[74]\end{array}$ & $(+) s s R N A$ & Brain stem, thalamus & $\mathrm{BBB}$ \\
\hline
\end{tabular}

dsDNA, double-stranded DNA; ssRNA, single-stranded RNA; CP, choroid plexus; BBB, blood-brain barrier; BCSFB, blood-cerebrospinal fluid barrier.

$[36,95,96]$ as well as the recently characterized immortalized human choroid plexus papilloma cell line (HIBCPP) [34, 48, 97]. The suitability and limitations of immortalized murine and human cell lines (low transepithelial electrical resistance (TEER) development and uncontentious TJ connections) have been studied intensely and restrictions for broader usage have been encountered $[18,98]$. In contrast, the immortalized polar cell line HIBCPP can be used as the first functional human in vitro model of the BCSFB $[34,95,99]$. Moreover, through the establishment of an inverted cell culture system with polar cells (Figure 2), it is possible to infect the cells from the physiologically relevant basolateral side (blood) and to investigate viral infection leading to migration of leukocytes from the basolateral (blood) to the apical side (CSF). This can be brought even closer to in vivo conditions through addition of cytokines and chemokines. Schneider et al. [48], for example, used the HIBCPP model in combination with physiologically relevant chemokines such as CXCL3 and CXCL12 to investigate the complex interactions and cooperation of T-lymphocytes after infection of HIBCPP with EV30.
Despite a range of in vitro and in vivo models, there are still many open questions about the pathogenesis of viral CNS disease. The exact role of the CNS barriers and specific leukocytes is yet to be validated. Strain specificity and different infectability of the cell in the CNS complicate the development of adequate infections models. Moreover, for many viruses we lack in vivo proof of specific host cell infection in animal models, which minimizes the validity of the deductions adaptable to human infection. A comparative analysis between the data obtained from animal experiments and human data remains difficult [100-102].

\section{Cytokines and Chemokine Involvement in Viral CNS Infection}

Cytokines are involved in almost all biological processes and maintain an important regulatory element. Most cytokines are polypeptide messenger molecules $(8-140 \mathrm{kDa})$, and some may also be glycosylated. Communication and interactions of 
cells are influenced or controlled through release of cytokines, by the cells themselves or other cells of the organism, that vary according to different stimuli [103]. They are involved in both proinflammatory and anti-inflammatory processes, referred to as T-helper 1- (Th1-) and T-helper 2- (Th2-) cytokines, respectively. Their biological function in the context of inflammatory response can be differentiated into four major groups: (1) innate immunity (IL-1, IL-5, IL-6, and IL-8); (2) management of inflammatory processes (IL-1, IL-4, and TGF$\beta)$; (3) lymphocyte activation and proliferation (IL-2 and IL4); and (4) leukocyte growth mediation (IL-1, IL-3, IL-5, and IL-6). If cytokines are involved in chemical attraction of cells they are referred to as chemokines, which are small molecules $(\sim 8-14 \mathrm{kDa})$ that can further be split into four major subgroups (CXC, CC, XC, and $\mathrm{CX} 3 \mathrm{C}$ ) depending on their structural organization of conserved cysteine residues in the amino terminus [103-105]. Immune responses, in particular trafficking and development of immune cells, are controlled through the superfluous synthesis and release of cytokines and chemokines $[105,106]$. A distinct profile of cytokines and chemokines leads to an effective and specific host defense and promotes leukocyte migration during viral CNS infection. During meningitis and encephalitis, an array of cytokines and chemokines has been demonstrated to be regulated including CCL2, CXCL10, CXCL12, IL-1 $\beta$, and TNF- $\alpha$ [107-110].

Interestingly, an upregulation of IL- 6 and TNF- $\alpha$ cytokines so far primarily associated with bacterial meningitis, has been detected in the cerebrospinal fluid of patients with aseptic viral meningitis. However, IL-6 is also involved in Tand B-cell recruitment [111]. The importance of IL-6 during the life cycle of immune cells has been described for $\mathrm{CD}_{4}^{+}$ T-cells. During the maturation process of B-cells, to produce functional antibodies, important steps are stimulated through this proinflammatory cytokine [112].

A crucial chemokine in the context of viral CNS infection is CXCL12, which is the second most highly conserved chemokine ligand and occupies a fundamental role in the immune surveillance of the CNS. Together with its receptors CXCR4 and CXCR7 it encourages leukocyte communication and connection in the perivascular space [113]. However, if a state of disease alters the homeostatic distribution of CXCL12 it can lead to a loss of polar expression of the chemokine, subsequently leading to an accumulation of $\mathrm{CXCR} 4^{+}$cells in the brain parenchyma, which may increase the severity of the disease. This has been observed in multiple sclerosis (MS) and its adapted mouse model for experimental autoimmune encephalomyelitis (EAE), where the loss of CXCL12CXCR4 interaction leads to augmented expression of Th1 inflammatory mediators and amplified parenchymal immune intrusion [114]. CXCL12 was also investigated by Schneider et al. [48] as a chemoattractant of T-lymphocytes. In a human in vitro model with HIBCPP cells CXCL12 stimulation led to an increased T-lymphocyte basolateral to apical migration, whereas stimulation with CXCL3 did not induce higher migration rates. A time dependent upregulation of CXCL1, CXCL2, CXCL3, IL-8, and CCL5 after infection with EV30 was observed. Taken together, this indicates an involvement of various other factors in the process of T-lymphocyte transmigration into the infected human CNS.

\section{Inflammatory Reaction Caused by Specific Viral Pathogens during CNS Infection}

In the next paragraphs we describe in more detail the specific inflammatory reactions caused by several viral pathogens during CNS infection known to date. Examples of the Retroviridae, Herpesviridae, Picornaviridae, Flaviviridae, Paramyxoviridae, and Togaviridae families will be discussed in relation to their effects on the CNS immune response and release of mediators.

6.1. Retroviridae. Of the family Retroviridae, two main viruses, the human T-lymphotropic virus-1 (HTLV-1) and HIV, are important CNS pathogens, of which we will focus on the latter. Many HIV-1 variants exist, which display a large range of genetic alterations [115]. These can cause numerous neurological disorders, some of which can lead to cognitive, motor, or behavioral disorders, which together are known as HIV-associated neurocognitive disorders (HAND) [116].

HIV has the ability to disrupt the BBB and invade the CNS in the course of primary infection. The mechanisms crucial for HIV-1 infection of the CNS through BBB disruption have been studied extensively in in vitro and in in vivo models $[31,57,117]$. The virus is able to survive in leukocytes, thereby evading the immune system or antiviral treatment. HIV can "hide" inside T-cells [118, 119] but also inside monocytes, macrophages [120], and dendritic cells [121]. The migration and survival of HIV within leukocytes ("Trojan horse") is of major advantage for the virus [31, 122]. These infected leukocytes may migrate to areas which cannot be reached with antiretroviral drugs and consequently HIV can persist and further replicate [123].

The composition of the specific monocyte populations can also change during HIV infection. The population of $\mathrm{CD}_{14}{ }^{+} \mathrm{CD} 16^{+}$monocytes (5-10\%) found in healthy individuals increases up to $40 \%$ following HIV infection. Furthermore, a stronger migration of infected $\mathrm{CD} 14^{+} \mathrm{CD} 16^{+}$monocytes, compared to noninfected monocytes, was observed in response to CCL2 in an in vitro BBB model consisting of a coculture of HBME and astrocytes [124]. Infected mature monocytes from the vascular system were shown to move into the CNS and release virulence factors, which activate adjacent macrophages, astrocytes, and microglia, which consequently synthesize and release inflammatory cytokines such as TNF- $\alpha$, IL-1 $\beta$, and IL- 6 . This array of inflammatory cytokines contributes to BBB disruption and to the development of several disorders related to HAND [125]. Experimental data indicate that HIV persists in the tissue of the host organism due to the continuous migration of monocytes from the peripheral vascular system to the inflamed CNS. The monocyte chemoattractant chemokine ligand 2 (CCL2), which binds to CCR2 (on monocytes), has been shown to be strongly increased in the CSF during HIV infection of the CNS which can lead to the migration of both infected and noninfected cells into the CSF [126].

Specific chemokines can also contribute to successful neuroinvasion of the invading pathogen. In healthy individuals the basal levels of CCL2 in the CNS are low. However, HIV-infected monocytes exhibit enhanced CCR2 expression 
and were demonstrated to migrate and disseminate into the CNS. Furthermore, the data indicate that the virus is involved in assuring constant high expression of CCR2 on peripheral blood mononuclear cells [122]. In the mouse brain it was possible to measure elevated levels of CCL2, CCL3, CCL4, CCL5, and CXCL10 after retroviral infection [127]. In patients with HAND elevated levels of IL-8, CCL2, CXCL10, and G-CSF have been measured in the cerebrospinal fluid (CSF) [128].

Taken together, CCR2-/CCL2-mediated migration of $\mathrm{CD} 14^{+} \mathrm{CD} 16^{+}$monocytes into the CNS may be critical during HIV-mediated CNS pathology.

6.2. Herpesviridae. Herpesviridae such as herpes simplex virus (HSV), varicella zoster virus (VZV), Epstein Barr virus (EBV), cytomegalovirus (CMV), and human herpes virus6 (HHV-6) are causes of acute encephalitis and to a lesser extent meningitis [129]. Particularly HSV-1, on which we will focus in the following, is known to be the most common causal agent of sporadic herpes simplex encephalitis (HSE) through infection of neurons in the trigeminal ganglia. HSV infection of dorsal root sensory ganglia may cause lifelong latency [130].

Within an incidence of about $1 / 250,000$ cases, HSE mainly affects small children (6 months to 3 years) and adults older than 50 years [131]. HSE is associated with a mortality rate of up to $50-70 \%$ when left untreated, and even with appropriate treatment the disease frequently causes long term-sequelae [132]. Even though HSE has been studied thoroughly, its exact pathogenesis is still only vaguely understood [131].

The process of immune cell migration from the perivascular space to the CNS is directed and amplified through varying expression levels of specific ligands and receptors. The most important receptors during HSV-1 infection are CCR2, CCR5, and CXCR3, which are linked to Th1 polarized activated T- and NK cell recruitment $[133,134]$. In a model of experimental autoimmune encephalitis (EAE) and HSV-1 infection, the interaction of CCL5/CCR5 is involved in T-cell recruitment into the CNS. The expression levels of the ligand CCL5, which is presented by T-cells and macrophages, played a crucial role during leukocyte migration [135]. In CCR5 ${ }^{-/-}$ mice a significant elevation in the chemokines CCL2, CCL5, CXCL9, and CXCL10 in the trigeminal ganglion and brainstem after HSV-1 infections was observed. Moreover, the increase of the chemokine expression was associated with a significant increase in virus burden and an increase in the infiltration of $\mathrm{CD}^{+}$and $\mathrm{CD}{ }^{+}$into the trigeminal ganglion and brainstem [136].

It is know that microglia and blood-borne immune cells such as macrophages, dendritic cells, and T-cells have surveillance functions in the CNS to control the entry of viruses such as John Cunningham virus (JCV), HIV, WNV, and HSV1 [137]. For example, mice lacking the principle subunit of the type 1 IFN receptor IFNAR-A1 have been shown to have a drastic reduction of viral surveillance, which can be led back to a decline in virus specific cytotoxic T-cells. In contrast, an increase in macrophages within the CNS of IFNAR-A1 deficient mice has been observed [138].
Additionally, the control of migration of immune cells from the blood to the infected tissue area and the maintenance of the unique and homeostatic immunological environment of the CNS can be largely attributed to CX3C chemokine receptor 1 (CX3CR1) and its ligand CX3CL1. The importance of these tightly regulated interactions has been identified in mice deficient in CCR2 and CX3CR1 receptors $[131,139]$.

In the same line with the abovementioned findings, HSV-1 mediated sequelae were found to be increased in CXCR3-deficient mice [140]. The Th1-mediated immunological response to infection arises from increased expression of CXCR3 on NK, $\mathrm{CD} 4^{+}$, and $\mathrm{CD}^{+}$cells. Furthermore, the interaction of CXCR3 with CXCL9 and CXCL10 is important throughout the immunological response. In particular, CXCL10 is strongly expressed in the CNS during early stages of HSV-1 infection, and deficiency has been shown to lead to increased mortality partially attributed to the hindered NK cells recruitment $[105,133]$. Finally, clinical studies demonstrated increased levels of CCL2, CCL3, CCL5, and CXCL8 in the CSF of HSV-1 infected humans [141].

In conclusion, particularly CCR2, CCR5, and CX3CR1 have suggested to be relevant during the pathogenesis of HSV CNS disease. Their expression levels, in combination with the availability of their respective ligands CCL2 and CCL5, have been linked to recruitment of activated immune cells at the site of infection in the CNS.

6.3. Picornaviridae. The Picornaviridae family contains linear, very small single-stranded RNA viruses, which modify and then utilize intracellular membranes in the host cells to replicate their genomic RNA [142]. After the broad implementation of polio vaccines, nonpolio enteroviruses (NPEV) are the main cause of viral CNS infections worldwide [3, 143]. NPEV are widespread and cause a range of diseases in humans such as meningitis, encephalitis, or meningoencephalitis. Furthermore, high levels of morbidity and mortality in humans can be observed in young children and infants infected with NPEV such as echovirus, enterovirus 71, or coxsackievirus [144].

CVB3, especially, has been used in several studies analyzing the pathogenesis of NPEV CNS infections. The chemokine profile and leukocyte migration have been studied by Tabor-Godwin et al., who showed a crucial involvement of CCL12 (commonly known as a monocyte attractant) during CVB3-infected nestin ${ }^{+}$myeloid cell migration across the BCSFB into the CNS [80]. They also found that CVB3 is able to infect neural stem cells and maintain viral persistence [46, 145]. These data indicate a "Trojan horse" entrance pathway of CVB3 exploiting its ability to infect nestin ${ }^{+}$myeloid cells. Additionally, it has been suggested that B-cells may be involved in the spread of the NPEV through the "Trojan horse" mechanism as well [45].

A close interaction between an immunological response and cytokines and chemokines can also be seen during the clinical course of an infection with Picornaviridae viruses. This has been demonstrated through a changing inflammatory profile after EV30 infection. A shift from proinflammatory 
mediators such as IL-6, IL-8, and IFN- $\gamma$ to the production of IL-10 or TGF- $\beta 1$, known to be anti-inflammatory cytokines, has been demonstrated in the CSF of children [146]. Furthermore, raised levels of IL- 8 and CXCL10 in the blood and CSF, respectively, have been measured in patients suffering from brain encephalitis caused by EV71 [147]. The Th1 Tlymphocyte-mediated immunological response to viruses during CNS infection, especially the chemical attraction of Th1 T-cells, has been demonstrated to rely on CXCL10. The prompt expression and release of this mediator allows a controlled initiation of the host response [109]. Additional chemokines were shown to be upregulated in the CSF of Picornaviridae-infected mice such as CCL2, CCL4, CCL5, CCL6, CXCL10, IL-10, and TGF- $\beta 1[146,148]$. Their role in human disease has to be further clarified.

Due to the sparse information on cytokine and chemokine involvement during NPEV CNS infection, further studies should be conducted in both in vitro and in animal models also involving various clinical isolated and outbreak strains to broaden the understanding of Picornaviridae infections in humans.

6.4. Flaviviridae. Flaviviridae viruses are positive sense, single stranded RNA viruses often infecting humans and mammals. Currently, over 70 species are part of this dominantly arthropod-borne, viral family, out of which especially dengue virus, Japanese encephalitis virus (JEV), and WNV cause severe CNS infections in humans [149]. Due to the increasing number of outbreaks caused by WNV over the last years in Europe and North America, we have focused on this species in this review.

The pathogenesis of WNV CNS infections has been studied in a range of animal models including monkey [150], rat [151], hamster [152], and horse [153]. The large array of experimental studies conducted in rodent models and their validity has been reviewed previously [154]. However, so far, neither an ideal animal nor an in vitro WNV infection model to study the CNS pathogenesis exists and all have their specific limitations, which will be discussed in this section.

To cause CNS infections the virus must penetrate both neural and extraneural barriers such as the BBB [84]. Interestingly, in an in vitro study with primary human BMEC infected with a neurovirulent WNV strain, it has been demonstrated that infection with WNV does not need BBB disruption to facilitate leucocyte transmigration. However, a high expression of cell adhesion molecules correlated with an increased WNV-infected immune cell migration [83].

Successful invasion of WNV into the CNS causes an activation and migration of leukocytes, mainly T-cells and monocytes. Overall, increased T-cell migration during WNV encephalitis has been attributed to the release of IL-1 $\beta$, CXCL10, CCL2, and CCL5 in the brain $[113,155,156]$. Interestingly, varying levels of CXCL10 synthesis throughout the infected CNS can lead to unbalanced inflammatory cell migration. In mice, strain specific WNV infection of cerebellar granule cell neurons but not uninfected neurons led to CXCL10 synthesis. The unbalanced chemoattraction leads to a more dominant immune cell migration to the cerebellum, leaving other parts of the infected CNS less affected [104, 157].
Furthermore, following WNV infection, neuronal secretion of CXCL10 has been shown to recruit CXCR3 ${ }^{+} \mathrm{CD}^{+}$cells $[155,157,158]$. During WNV infection in mice, a more elevated $\mathrm{CD}^{+}$migration compared to $\mathrm{CD} 4^{+}$T-lymphocytes into the CNS could also be observed [158]. A further study by Shirato et al. [159] on chemokine involvement in WNV CNS disease showed a highly elevated chemokine expression profile of CCL3, CCL4, and CCL5 in the CNS of mice infected with a lethal WNV strain isolated in New York. In the infected mouse brain, a vastly enhanced expression of CCL3, CCL4, CCL5, and CXCL10 was observed on mRNA level. This model also allowed demonstration of elevated B-cell and monocyteactivating chemokine (BMAC) levels (known as CXCL14 in humans) during stages of advanced infection.

Recently, the role of CXCL12 has also been addressed in murine WNV models. Due to elevated CXCL12 levels in the perivascular space, leukocytes accumulated but did not penetrate into the CNS directly. Only once was CXCL12 downregulated and subsequently, its concentration was decreased in the perivascular space; immune cells migrated across the brain barriers into the CNS. A functional cooperation between the ligand CXCL12 in the perivascular space and its receptor CXCR4 on the host cells is essential for leukocyte migration into the CNS. This has been underlined through inhibition studies on CXCR4, which overall increased Tlymphocyte entry into the CNS parenchyma and subsequently raised survival rates and minimized neuropathology [160].

Another important cytokine-receptor interaction in the context of CNS infection has been demonstrated between the IL-1 cytokine family and its receptor IL-1R1 [161]. Its involvement during WNV CNS infection has been studied using a mouse model, illustrating an overall more severe infection in mice lacking functional IL-1R1 receptors. The ligand, IL- $1 \beta$, is mainly produced by $\mathrm{CD} 11 \mathrm{~b}^{+} \mathrm{CD} 45^{\text {high }}$ monocytes migrating into the CNS. IL- $1 \beta$ functionality is required for correct interaction of CXCR4 and CXCL12, which tightly regulates the migration across an endothelial cell layer. Unaltered interaction between the receptor and its ligand leads to $\mathrm{CXCR}^{+}$cell retention in the microvascular system of the CNS [113]. Additionally, this cytokine sustains and controls the effector activity of T-lymphocytes but not B-lymphocytes. The functionality of active T-lymphocytes during inflammation has been shown to be reduced only in $\mathrm{CD} 4^{+}$but not in $\mathrm{CD}^{+}$cells. However, $\mathrm{CD}^{+}$and $\mathrm{CD} 4^{+} \mathrm{T}$-cells activated by antigen presenting cell (APC) can further be stimulated with IL- $1 \beta$, causing enhanced migration and cytokine synthesis $[162,163]$. Interestingly, IL- $1 \beta$ was shown to be involved in the inflammasome signaling complex and exhibited increased susceptibility to WNV pathogenesis in vivo. Moreover, the reduction of IL- $1 \beta$ effects impaired the quality of the effector $\mathrm{CD}^{+} \mathrm{T}$-cell response and reduced antiviral activity within the CNS. IL-1 $\beta$ signaling synergized with type 1 IFN to suppress WNV replication in neurons by this controlled virus replication within the CNS [164].

Activated monocytes are also essential for viral clearance and host survival in the CNS. Prior to monocyte migration into the WNV-infected CNS, a rapid infiltration of monocytes into the vascular system can be observed [165]. 
Furthermore, the importance of CCL2 during monocytosis was underlined, whilst showing that viral clearance is independent of CCL2 binding to CCR2. CD8 ${ }^{+}$T-cells and PMN exhibit a CCL7 dependent migration into the CNS succeeding WNV infection leading to increased viral elimination and survival [165]. However, Ly6C $\mathrm{C}^{\text {high }}$ inflammatory monocytes have shown to cause more severe neuropathological problems once they have migrated to the infected brain during viral CNS disease [166]. The chemokines CCL2 and CCL7, which bind to CCR2 on monocytes, are known to be of substantial importance during inflammatory monocyte release from the bone marrow [167].

In summary, WNV-induced CNS disease involves the release of a broad range of cytokines and chemokines. Particularly, IL-1 $\beta$ stands out with its important role in attraction of activated antigen specific immune cells and involvement in regulation of WNV-induced neuroinflammation. Due to a lack of consistent immunological data on WNV infection in animals and humans, further studies are needed to investigate WNV CNS infection. These implications have been critically reviewed by Trobaugh and Green [168]. On a genetic level, significant differences in expression patterns during an acute inflammatory response could be observed between orthologues of mice and human [101]. However, the Collaborative Cross (CC) mouse model has been suggested to mimic the genetic diversity of human appropriately and therefore to be relevant to study genetic variations during WNV infection [102]. Recently, a previously unappreciated phenomenon in WNV infection models has been observed. The authors described notable intragroup variations in the end-point disease in mice infected with different WNV strains of intermediate virulence [100]. Taken together, optimized models need to be identified to verify previous in vitro and in vivo models to translate observations made in rodents to humans.

6.5. Paramyxoviridae. Viruses belonging to the Paramyxoviridae family have a single negative sense stranded RNA genome and include well known species such as mumps $(\mathrm{MuV})$ and measles $(\mathrm{MV})$. In the following, we will highlight primarily findings in measles CNS pathogenesis.

CNS involvement in measles can be classified into primary measles encephalitis, postmeasles encephalitis, measles inclusion body encephalitis, and subacute sclerosing panencephalitis [69]. CXCL10- and CCL5-mediated lymphomonocytic infiltration during measles CNS infection has been demonstrated in a transgenic mouse model [169]. When depleting CXCL10 and/or CCL5, T-cell migration into the brain parenchyma was significantly altered. Up to $40 \%$ overall reduction of $\mathrm{CD}^{+}$and $\mathrm{CD}^{+}$T-lymphocyte recruitment in mice lacking available CXCL10 and a reduced $\mathrm{CD}^{+}$but not $\mathrm{CD}^{+}$T-cell migration after the application of antiCCL5 antibody was observed. The neuronal presentation and disease outcome of patients is possibly further influenced through the involvement of different cell types in the CNS such as astrocytes and microglia [169].

The second important member of this viral family is the mumps virus. Only scant data exist, demonstrating the role of cytokines, chemokines, and leukocytes in mumps CNS infection. Infected mononuclear cell migration across the BCSFB of newborn hamsters has been shown to mediate meningoencephalitis [70]. Moreover, in clinical studies, children with mumps meningitis exhibit a significantly higher concentration of IL-8, IL-10, IL-12, IL-13, and IFN- $\gamma$ in the CSF compared to children with meningitis caused by other viruses [170].

Interestingly, measles and mumps virus have not enjoyed the same amount of attention with regard to pathogenic research as other neurotropic viruses, despite the high clinical burden. This might be due to the availability of well efficacious vaccines. The cytokine and chemokine profiles and subsequent leukocyte migration should be the focus of future studies.

6.6. Togaviridae. This viral family has a linear singlestranded positive sense RNA genome and can naturally be encountered in mosquitos, humans, birds, and mammals. The arthropod-borne CHIKV, belonging to the genus of Alphaviruses, has recently been under more thorough investigation, due to several severe epidemics worldwide. The virus has been classified into three genotypes, which evaluate the origin in terms of geographical regions: (1) West Africa, (2) East/Central/South Africa (ECSA), and (3) Asia [171173]. During outbreaks in 2006, strains isolated from patients showed distinct genome variations, which led to the suggestion that these molecular adaptations (mutations) enhanced the pathogenicity [174]. Usually, neurological problems occur only intermittently; however, with the novel ECSA genotype, higher levels have been observed in neonates as well as in adults. A clinical study elucidated that an array of unusually high neurological complications arose from infection with these CHIKV-strains. In $16.3 \%$ of patients, neurological affection was observed. Out of these, 55.1\% suffered from encephalitis [175].

The CHIKV has been shown to gain access into the $\mathrm{CNS}$ via the olfactory nerve. Intranasal injection of BALB/c mice with the CHIKV causes neuronal degeneration, further leading to tissue necrosis [176]. Scant data exist about the interaction of CHIKV with primary human cells. Studies in vitro using endothelial cells hCMEC/D3, epithelial cells A549, lymphocytes, and monocytes indicated very low infection and/or replication rates for CHIKV [177]. Although CHIKV infection of human in in vitro models has been analyzed in a few studies, appropriate in vivo models for CNS infection are scarce.

Various proinflammatory chemokines, including CCL2, IL- 6 , and TNF- $\alpha$ were shown to be upregulated in the mouse brain after CHIKV infection, enhancing T-cell and macrophage attraction. The authors underline the importance of anti-inflammatory stimulus through IL- 4 once the infection has been controlled. IL- 4 hinders the breakdown of the BBB which would allow further virus entry and has the additional characteristic of activating T- and B-cells [178]. However, high levels of IL-10, also associated with CHIKV infection in mice, may act as immunosuppressive and impede Th1 and NK cell functionality [179]. The virus has also been shown to target astrocytes in the CNS, both in vitro and in vivo, which in turn activates dendritic cells [73]. 
In conclusion, despite some existing data, the understanding of the neuropathogenesis of CHIKV is still very limited. Nevertheless, the research conducted suggests neurotropic characteristics of the virus. However, data on leukocyte activity and immune response following CNS infection with CHIKV hardly exist. Due to an increasing observation of clinical CNS, involvement in this area is of great interest for further research.

\section{Conclusion and Fields for Future Research}

In this review we highlight complex interactions between different CNS-tropic viruses, inflammatory mediators and leukocytes, and the CNS. However, due to the complex nature of controlled biological processes in humans, the task to identify specific cytokine and chemokine profile for each pathogen is demanding. Adequate models and additional in vitro, in vivo, and clinical studies analyzing CNS inflammation and leukocyte migration in the context of viral CNS infections are warranted. The thorough understanding of the complex and interrelated inflammatory mechanisms as well as identifying universal mediators promoting CNS inflammation is essential for the development of new diagnostic and treatment strategies.

\section{Competing Interests}

The authors declare that they have no competing interests.

\section{Acknowledgments}

The authors would like to thank Moa Li Nasarek and Jennie Hansson for their assistance in the figure preparation. Special thanks are due to Dr. rer. nat. Julia Borkowski and Dr. rer. nat. Martin März for their constructive comments on the paper. The authors acknowledge the financial support of the Deutsche Forschungsgemeinschaft and Ruprecht-KarlsUniversität Heidelberg within the funding programme Open Access Publishing.

\section{References}

[1] P. A. Swanson II and D. B. McGavern, "Viral diseases of the central nervous system," Current Opinion in Virology, vol. 11, pp. 44-54, 2015.

[2] A. G. Michos, V. P. Syriopoulou, C. Hadjichristodoulou et al., "Aseptic meningitis in children: analysis of 506 cases," PloS ONE, vol. 2, no. 7, article e674, 2007.

[3] H. A. Rotbart, "Viral meningitis," Seminars in Neurology, vol. 20, no. 3, pp. 277-292, 2000.

[4] P. Rantakallio, M. Leskinen, and L. von Wendt, "Incidence and prognosis of central nervous system infections in a birth cohort of 12,000 children," Scandinavian Journal of Infectious Diseases, vol. 18, no. 4, pp. 287-294, 1986.

[5] P. Kivisäkk, D. J. Mahad, M. K. Callahan et al., "Human cerebrospinal fluid central memory $\mathrm{CD}^{+} \mathrm{T}$ cells: evidence for trafficking through choroid plexus and meninges via P-selectin," Proceedings of the National Academy of Sciences of the United States of America, vol. 100, no. 14, pp. 8389-8394, 2003.
[6] M. T. De Graaf, P. A. E. Sillevis Smitt, R. L. Luitwieler et al., "Central memory $\mathrm{CD} 4^{+} \mathrm{T}$ cells dominate the normal cerebrospinal fluid," Cytometry Part B: Clinical Cytometry, vol. 80, no. 1, pp. 43-50, 2011.

[7] S. Cepok, B. Rosche, V. Grummel et al., "Short-lived plasma blasts are the main B cell effector subset during the course of multiple sclerosis," Brain, vol. 128, no. 7, pp. 1667-1676, 2005.

[8] S. Cepok, G. von Geldern, V. Grummel et al., "Accumulation of class switched IgD-IgM- memory B cells in the cerebrospinal fluid during neuroinflammation," Journal of Neuroimmunology, vol. 180, no. 1-2, pp. 33-39, 2006.

[9] D. Michlmayr, C. S. McKimmie, M. Pingen et al., "Defining the chemokine basis for leukocyte recruitment during viral encephalitis," Journal of virology, vol. 88, no. 17, pp. 9553-9567, 2014.

[10] K. Fukushima, A. Ishiguro, and T. Shimbo, “Transient elevation of granulocyte colony-stimulating factor levels in cerebrospinal fluid at the initial stage of aseptic meningitis in children," Pediatric Research, vol. 37, no. 2, pp. 160-164, 1995.

[11] D. Demeestere, C. Libert, and R. E. Vandenbroucke, "Clinical implications of leukocyte infiltration at the choroid plexus in (neuro)inflammatory disorders," Drug Discovery Today, vol. 20, no. 8, pp. 928-941, 2015.

[12] N. J. Abbott, A. A. K. Patabendige, D. E. M. Dolman, S. R. Yusof, and D. J. Begley, "Structure and function of the blood-brain barrier," Neurobiology of Disease, vol. 37, no. 1, pp. 13-25, 2010.

[13] N. J. Abbott, L. Rönnbäck, and E. Hansson, "Astrocyteendothelial interactions at the blood-brain barrier," Nature Reviews Neuroscience, vol. 7, no. 1, pp. 41-53, 2006.

[14] S. Tietz and B. Engelhardt, "Brain barriers: crosstalk between complex tight junctions and adherens junctions," The Journal of Cell Biology, vol. 209, no. 4, pp. 493-506, 2015.

[15] K. R. Spindler and T.-H. Hsu, "Viral disruption of the bloodbrain barrier," Trends in Microbiology, vol. 20, no. 6, pp. 282290, 2012.

[16] N. Strazielle and J.-F. Ghersi-Egea, "Choroid plexus in the central nervous system: biology and physiopathology," Journal of Neuropathology and Experimental Neurology, vol. 59, no. 7, pp. 561-574, 2000.

[17] H. Wolburg and W. Paulus, "Choroid plexus: biology and pathology," Acta Neuropathologica, vol. 119, no. 1, pp. 75-88, 2010.

[18] N. Strazielle and J.-F. Ghersi-Egea, "In vitro models of the blood-cerebrospinal fluid barrier and their use in neurotoxicological research," in Cell Culture Techniques, vol. 56 of Neuromethods, pp. 161-184, Humana Press, 2011.

[19] H. Wolburg and A. Lippoldt, "Tight junctions of the bloodbrain barrier: development, composition and regulation," Vascular Pharmacology, vol. 38, no. 6, pp. 323-337, 2002.

[20] B. Engelhardt, "Development of the blood-brain interface," in Blood-Brain Barriers, pp. 9-39, Wiley-VCH Verlag GmbH \& Co. KGaA, Weinheim, Germany, 2007.

[21] C. Lehner, R. Gehwolf, H. Tempfer et al., "Oxidative stress and blood-brain barrier dysfunction under particular consideration of matrix metalloproteinases," Antioxidants and Redox Signaling, vol. 15, no. 5, pp. 1305-1323, 2011.

[22] A. Hartsock and W. J. Nelson, "Adherens and tight junctions: structure, function and connections to the actin cytoskeleton," Biochimica et Biophysica Acta (BBA)_Biomembranes, vol. 1778, no. 3, pp. 660-669, 2008. 
[23] M. Coureuil, O. Join-Lambert, H. Lécuyer, S. Bourdoulous, S. Marullo, and X. Nassif, "Mechanism of meningeal invasion by Neisseria meningitidis," Virulence, vol. 3, no. 2, pp. 164-172, 2012.

[24] E. Mairey, A. Genovesio, E. Donnadieu et al., "Cerebral microcirculation shear stress levels determine Neisseria meningitidis attachment sites along the blood-brain barrier," Journal of Experimental Medicine, vol. 203, no. 8, pp. 1939-1950, 2006.

[25] X. Nassif, S. Bourdoulous, E. Eugène, and P.-O. Couraud, "How do extracellular pathogens cross the blood-brain barrier?" Trends in Microbiology, vol. 10, no. 5, pp. 227-232, 2002.

[26] F. Iovino, G. Molema, and J. J. E. Bijlsma, "Streptococcus pneumoniae interacts with pIgR expressed by the brain microvascular endothelium but does not co-localize with PAF receptor," PLoS ONE, vol. 9, no. 5, Article ID e97914, 2014.

[27] A. Y. Jong, M. F. Stins, S.-H. Huang, S. H. M. Chen, and K. S. Kim, "Traversal of Candida albicans across human blood-brain barrier in vitro," Infection and Immunity, vol. 69, no. 7, pp. 45364544, 2001.

[28] Y. Liu, R. Mittal, N. V. Solis, N. V. Prasadarao, and S. G. Filler, "Mechanisms of candida albicans trafficking to the brain," PLoS Pathogens, vol. 7, no. 10, Article ID e1002305, 2011.

[29] T. Wang, T. Town, L. Alexopoulou, J. F. Anderson, E. Fikrig, and R. A. Flavell, "Toll-like receptor 3 mediates West Nile virus entry into the brain causing lethal encephalitis," Nature Medicine, vol. 10, no. 12, pp. 1366-1373, 2004.

[30] M. S. Diamond and R. S. Klein, "West Nile virus: crossing the blood-brain barrier," Nature Medicine, vol. 10, no. 12, pp. 12941295, 2004.

[31] V. S. R. Atluri, M. Hidalgo, T. Samikkannu et al., "Effect of human immunodeficiency virus on blood-brain barrier integrity and function: an update," Frontiers in Cellular Neuroscience, vol. 9, article 212, 2015.

[32] H. Wang, J. Sun, and H. Goldstein, "Human immunodeficiency virus type 1 infection increases the in vivo capacity of peripheral monocytes to cross the blood-brain barrier into the brain and the in vivo sensitivity of the blood-brain barrier to disruption by lipopolysaccharide," Journal of Virology, vol. 82, no. 15, pp. 7591-7600, 2008.

[33] J. Sellner, F. Simon, U. Meyding-Lamade, and S. L. Leib, "Herpes-simplex virus encephalitis is characterized by an early MMP-9 increase and collagen type IV degradation," Brain Research, vol. 1125, no. 1, pp. 155-162, 2006.

[34] C. Schwerk, T. Papandreou, D. Schuhmann et al., "Polar invasion and translocation of Neisseria meningitidis and Streptococcus suis in a novel human model of the blood-cerebrospinal fluid barrier," PLoS ONE, vol. 7, no. 1, Article ID e30069, 2012.

[35] S. E. Sanford, "Gross and histopathological findings in unusual lesions caused by Streptococcus suis in pigs. II. Central nervous system lesions," Canadian Journal of Veterinary Research, vol. 51, no. 4, pp. 486-489, 1987.

[36] T. Tenenbaum, T. Papandreou, D. Gellrich et al., "Polar bacterial invasion and translocation of Streptococcus suis across the blood-cerebrospinal fluid barrier in vitro," Cellular Microbiology, vol. 11, no. 2, pp. 323-336, 2009.

[37] B. Pron, M.-K. Taha, C. Rambaud et al., "Interaction of Neisseria meningitidis with the components of the blood-brain barrier correlates with an increased expression of PilC," Journal of Infectious Diseases, vol. 176, no. 5, pp. 1285-1292, 1997.
[38] J. Guarner, P. W. Greer, A. Whitney et al., "Pathogenesis and diagnosis of human meningococcal disease using immunohistochemical and PCR assays," The American Journal of Clinical Pathology, vol. 122, no. 5, pp. 754-764, 2004.

[39] A. L. Smith, "Pathogenesis of Haemophilus influenzae meningitis," Pediatric Infectious Disease Journal, vol. 6, no. 8, pp. 783786, 1987.

[40] B. L. Wiedermann, E. P. Hawkins, G. S. Johnson, L. B. Lamberth, E. O. Mason, and S. L. Kaplan, "Pathogenesis of labyrinthitis associated with Haemophilus influenzae type b meningitis in infant rats," The Journal of Infectious Diseases, vol. 153, no. 1, pp. 27-32, 1986.

[41] R. S. Daum, D. W. Scheifele, P. V. Syriopoulou, D. Averill, and A. L. Smith, "Ventricular involvement in experimental Hemophilus influenzae meningitis," Journal of Pediatrics, vol. 93, no. 6, pp. 927-930, 1978.

[42] T. Gründler, N. Quednau, C. Stump et al., "The surface proteins InlA and InlB are interdependently required for polar basolateral invasion by Listeria monocytogenes in a human model of the blood-cerebrospinal fluid barrier," Microbes and Infection, vol. 15, no. 4, pp. 291-301, 2013.

[43] E. Mylonakis, E. L. Hohmann, and S. B. Calderwood, "Central nervous system infection with Listeria monocytogenes: 33 years' experience at a general hospital and review of 776 episodes from the literature," Medicine, vol. 77, no. 5, pp. 313-336, 1998.

[44] N. Prats, V. Briones, M. M. Blanco et al., "Choroiditis and meningitis in experimental murine infection with Listeria monocytogenes," European Journal of Clinical Microbiology \& Infectious Diseases, vol. 11, no. 8, pp. 744-747, 1992.

[45] R. E. Rhoades, J. M. Tabor-Godwin, G. Tsueng, and R. Feuer, "Enterovirus infections of the central nervous system," Virology, vol. 411, no. 2, pp. 288-305, 2011.

[46] R. Feuer, I. Mena, R. R. Pagarigan, S. Harkins, D. E. Hassett, and J. L. Whitton, "Coxsackievirus B3 and the neonatal CNS: the roles of stem cells, developing neurons, and apoptosis in infection, viral dissemination, and disease," American Journal of Pathology, vol. 163, no. 4, pp. 1379-1393, 2003.

[47] T. Couderc, F. Chrétien, C. Schilte et al., "A mouse model for Chikungunya: young age and inefficient type-I interferon signaling are risk factors for severe disease," PLoS Pathogens, vol. 4, no. 2, article e29, 2008.

[48] H. Schneider, C. E. Weber, J. Schoeller et al., "Chemotaxis of T-cells after infection of human choroid plexus papilloma cells with Echovirus 30 in an in vitro model of the bloodcerebrospinal fluid barrier," Virus Research, vol. 170, no. 1-2, pp. 66-74, 2012.

[49] C. Schwerk, T. Tenenbaum, K. S. Kim, and H. Schroten, “The choroid plexus-a multi-role player during infectious diseases of the CNS," Frontiers in Cellular Neuroscience, vol. 9, article 80, 2015.

[50] R. Ren and V. R. Racaniello, "Poliovirus spreads from muscle to the central nervous system by neural pathways," Journal of Infectious Diseases, vol. 166, no. 4, pp. 747-752, 1992.

[51] V. R. Racaniello, "One hundred years of poliovirus pathogenesis," Virology, vol. 344, no. 1, pp. 9-16, 2006.

[52] E. M. Ponnuraj, T. Jacob John, M. J. Levin, and E. A. F. Simoes, "Sabin attenuated LSc/2ab strain of poliovirus spreads to the spinal cord from a peripheral nerve in bonnet monkeys (Macaca radiata)," Journal of General Virology, vol. 82, part 6, pp. 1329-1338, 2001. 
[53] I. Mori, Y. Nishiyama, T. Yokochi, and Y. Kimura, "Olfactory transmission of neurotropic viruses," Journal of NeuroVirology, vol. 11, no. 2, pp. 129-137, 2005.

[54] Y. Becker, "HSV-1 brain infection by the olfactory nerve route and virus latency and reactivation may cause learning and behavioral deficiencies and violence in children and adults: a point of view," Virus Genes, vol. 10, no. 3, pp. 217-226, 1995.

[55] H. Cho and M. S. Diamond, "Immune responses to west nile virus infection in the central nervous system," Viruses, vol. 4, no. 12, pp. 3812-3830, 2012.

[56] N. Nathanson, "The pathogenesis of poliomyelitis: what we don't know," Advances in Virus Research, vol. 71, pp. 1-50, 2008.

[57] F. González-Scarano and J. Martín-García, “The neuropathogenesis of AIDS," Nature Reviews Immunology, vol. 5, no. 1, pp. 69-81, 2005.

[58] D. Gilden, M. Nagel, R. Cohrs, R. Mahalingam, and N. Baird, "Varicella zoster virus in the nervous system," F1000Research, vol. 4, article 1356, 2015.

[59] M. C.-J. Cheeran, J. R. Lokensgard, and M. R. Schleiss, "Neuropathogenesis of congenital cytomegalovirus infection: disease mechanisms and prospects for intervention," Clinical Microbiology Reviews, vol. 22, no. 1, pp. 99-126, 2009.

[60] H. Agut, P. Bonnafous, and A. Gautheret-Dejean, "Laboratory and clinical aspects of human herpesvirus 6 infections," Clinical Microbiology Reviews, vol. 28, no. 2, pp. 313-335, 2015.

[61] P. G. E. Kennedy and A. Chaudhuri, "Herpes simplex encephalitis," Journal of Neurology Neurosurgery and Psychiatry, vol. 73, no. 3, pp. 237-238, 2002.

[62] S. Hoover, J. Ross, and J. Cohen, Epstein-Barr Virus, Williams \& Wilkins, Philadelphia, Pa, USA, 2004.

[63] A. Muehlenbachs, J. Bhatnagar, and S. R. Zaki, "Tissue tropism, pathology and pathogenesis of enterovirus infection," The Journal of Pathology, vol. 235, no. 2, pp. 217-228, 2015.

[64] L. N. Luethy, A. K. Erickson, P. R. Jesudhasan, M. Ikizler, T. S. Dermody, and J. K. Pfeiffer, "Comparison of three neurotropic viruses reveals differences in viral dissemination to the centrl nervous system," Virology, vol. 487, pp. 1-10, 2016.

[65] M. A. Verboon-Maciolek, F. Groenendaal, C. D. Hahn et al., "Human parechovirus causes encephalitis with white matter injury in neonates," Annals of Neurology, vol. 64, no. 3, pp. 266$273,2008$.

[66] K. Blom, M. Braun, J. Pakalniene et al., "Specificity and dynamics of effector and memory CD8 $\mathrm{T}$ cell responses in human tickborne encephalitis virus infection," PLoS Pathogens, vol. 11, no. 1, Article ID e1004622, 2015.

[67] G. J. Sips, J. Wilschut, and J. M. Smit, "Neuroinvasive flavivirus infections," Reviews in Medical Virology, vol. 22, no. 2, pp. 69-87, 2012.

[68] F. Li, Y. Wang, L. Yu et al., "Viral infection of the central nervous system and neuroinflammation precede blood-brain barrier disruption during Japanese encephalitis virus infection," Journal of Virology, vol. 89, no. 10, pp. 5602-5614, 2015.

[69] D. L. Fisher, S. Defres, and T. Solomon, "Measles-induced encephalitis," Quarterly Journal of Medicine, vol. 108, no. 3, pp. 177-182, 2015.

[70] J. S. Wolinsky, T. Klassen, and J. R. Baringer, "Persistence of neuroadapted mumps virus in brains of newborn hamsters after intraperitoneal inoculation," Journal of Infectious Diseases, vol. 133, no. 3, pp. 260-267, 1976.
[71] D. C. Hooper, A. Roy, D. A. Barkhouse, J. Li, and R. B. Kean, "Rabies virus clearance from the central nervous system," Advances in Virus Research, vol. 79, pp. 55-71, 2011.

[72] M. W. Ferenczy, L. J. Marshall, C. D. S. Nelson et al., "Molecular biology, epidemiology, and pathogenesis of progressive multifocal leukoencephalopathy, the JC virus-induced demyelinating disease of the human brain," Clinical Microbiology Reviews, vol. 25, no. 3, pp. 471-506, 2012.

[73] T. Das, J. J. Hoarau, M. C. Jaffar Bandjee, M. Marianne, and P. Gasque, "Multifaceted innate immune responses engaged by astrocytes, microglia and resident dendritic cells against Chikungunya neuroinfection," Journal of General Virology, vol. 96, part 2, pp. 294-310, 2015.

[74] M. Ludlow, J. Kortekaas, C. Herden et al., "Neurotropic virus infections as the cause of immediate and delayed neuropathology," Acta Neuropathologica, vol. 131, no. 2, pp. 159-184, 2016.

[75] K. S. Kim, "Mechanisms of microbial traversal of the bloodbrain barrier," Nature Reviews Microbiology, vol. 6, no. 8, pp. 625-634, 2008.

[76] J. E. Oakes, "Invasion of the central nervous system by herpes simplex virus type 1 after subcutaneous inoculation of immunosuppressed mice," Journal of Infectious Diseases, vol. 131, no. 1, pp. 51-57, 1975.

[77] N. Q. Liu, A. S. Lossinsky, W. Popik et al., "Human immunodeficiency virus type 1 enters brain microvascular endothelia by macropinocytosis dependent on lipid rafts and the mitogenactivated protein kinase signaling pathway," Journal of Virology, vol. 76, no. 13, pp. 6689-6700, 2002.

[78] M. Fiala, D. J. Looney, M. Stins et al., “TNF- $\alpha$ opens a paracellular route for HIV-1 invasion across the blood-brain barrier," Molecular Medicine, vol. 3, no. 8, pp. 553-564, 1997.

[79] C. Bleau, A. Filliol, M. Samson, and L. Lamontagne, "Brain invasion by mouse hepatitis virus depends on impairment of tight junctions and beta interferon production in brain microvascular endothelial cells," Journal of Virology, vol. 89, no. 19, pp. 9896-9908, 2015.

[80] J. M. Tabor-Godwin, C. M. Ruller, N. Bagalso et al., "A novel population of myeloid cells responding to coxsackievirus infection assists in the dissemination of virus within the neonatal CNS," The Journal of Neuroscience, vol. 30, no. 25, pp. 8676-8691, 2010.

[81] J. E. Hazleton, J. W. Berman, and E. A. Eugenin, "Novel mechanisms of central nervous system damage in HIV infection," HIV AIDS, vol. 2, pp. 39-49, 2010.

[82] A. Mahadevan, S. K. Shankar, P. Satishchandra et al., "Characterization of human immunodeficiency virus (HIV)-infected cells in infiltrates associated with CNS opportunistic infections in patients with HIV clade C infection," Journal of Neuropathology and Experimental Neurology, vol. 66, no. 9, pp. 799-808, 2007.

[83] S. Verma, Y. Lo, M. Chapagain et al., "West Nile virus infection modulates human brain microvascular endothelial cells tight junction proteins and cell adhesion molecules: transmigration across the in vitro blood-brain barrier," Virology, vol. 385, no. 2, pp. 425-433, 2009.

[84] W. W. Suen, N. A. Prow, R. A. Hall, and H. BielefeldtOhmann, "Mechanism of west nile virus neuroinvasion: a critical appraisal," Viruses, vol. 6, no. 7, pp. 2796-2825, 2014.

[85] S. M. Stamatovic, R. F. Keep, and A. V. Andjelkovic, "Brain endothelial cell-cell junctions: how to 'open' the blood brain 
barrier," Current Neuropharmacology, vol. 6, no. 3, pp. 179-192, 2008.

[86] B. P. Daniels, D. W. Holman, L. Cruz-Orengo, H. Jujjavarapu, D. M. Durrant, and R. S. Klein, "Viral pathogen-associated molecular patterns regulate blood-brain barrier integrity via competing innate cytokine signals," mBio, vol. 5, no. 5, Article ID e01476-14, 2014.

[87] R. M. Ransohoff and B. Engelhardt, "The anatomical and cellular basis of immune surveillance in the central nervous system," Nature Reviews Immunology, vol. 12, no. 9, pp. 623-635, 2012.

[88] Y. He, Y. Yao, S. E. Tsirka, and Y. Cao, "Cell-culture models of the blood-brain barrier," Stroke, vol. 45, no. 8, pp. 2514-2526, 2014.

[89] D. E. Eigenmann, G. Xue, K. S. Kim, A. V. Moses, M. Hamburger, and M. Oufir, "Comparative study of four immortalized human brain capillary endothelial cell lines, hCMEC/D3, hBMEC, TY10, and BB19, and optimization of culture conditions, for an in vitro blood-brain barrier model for drug permeability studies," Fluids and Barriers of the CNS, vol. 10, no. 1, article 33, 2013.

[90] C. B. Coyne, K. S. Kim, and J. M. Bergelson, "Poliovirus entry into human brain microvascular cells requires receptor-induced activation of SHP-2," EMBO Journal, vol. 26, no. 17, pp. 40164028, 2007.

[91] B. Brandenburg, L. Y. Lee, M. Lakadamyali, M. J. Rust, X. Zhuang, and J. M. Hogle, "Imaging poliovirus entry in live cells," PLoS Biology, vol. 5, no. 7, article e183, 2007.

[92] Y. Persidsky, "Model systems for studies of leukocyte migration across the blood-brain barrier," Journal of NeuroVirology, vol. 5, no. 6, pp. 579-590, 1999.

[93] W. Zheng and Q. Zhao, "Establishment and characterization of an immortalized Z310 choroidal epithelial cell line from murine choroid plexus," Brain Research, vol. 958, no. 2, pp. 371-380, 2002.

[94] L. Z. Shi, G. J. Li, S. Wang, and W. Zheng, "Use of Z310 cells as an in vitro blood-cerebrospinal fluid barrier model: tight junction proteins and transport properties," Toxicology in Vitro, vol. 22, no. 1, pp. 190-199, 2008.

[95] M. Schroten, F.-G. Hanisch, N. Quednau et al., "A novel porcine in vitro model of the blood-cerebrospinal fluid barrier with strong barrier function," PLoS ONE, vol. 7, no. 6, Article ID e39835, 2012.

[96] M. Haselbach, J. Wegener, S. Decker, C. Engelbertz, and H.-J. Galla, "Porcine choroid plexus epithelial cells in culture: regulation of barrier properties and transport processes," Microscopy Research and Technique, vol. 52, no. 1, pp. 137-152, 2001.

[97] I. Ishiwata, C. Ishiwata, E. Ishiwata et al., "Establishment and characterization of a human malignant choroids plexus papilloma cell line (HIBCPP)," Human Cell, vol. 18, no. 1, pp. 67-72, 2005.

[98] J. Kläs, H. Wolburg, T. Terasaki, G. Fricker, and V. Reichel, "Characterization of immortalized choroid plexus epithelial cell lines for studies of transport processes across the bloodcerebrospinal fluid barrier," Cerebrospinal Fluid Research, vol. 7, article 11, 2010.

[99] T. Tenenbaum, U. Steinmann, C. Friedrich, J. Berger, C. Schwerk, and H. Schroten, "Culture models to study leukocyte trafficking across the choroid plexus," Fluids and Barriers of the CNS, vol. 10, no. 1, article 1, 2013.

[100] W. W. Suen, N. A. Prow, Y. X. Setoh et al., "End-point disease investigation for virus strains of intermediate virulence as illustrated by flavivirus infections," Journal of General Virology, vol. 97, no. 2, pp. 366-377, 2016.

[101] J. Seok, H. S. Warren, A. G. Cuenca et al., "Genomic responses in mouse models poorly mimic human inflammatory diseases," Proceedings of the National Academy of Sciences of the United States of America, vol. 110, no. 9, pp. 3507-3512, 2013.

[102] J. B. Graham, S. Thomas, J. Swarts et al., "Genetic diversity in the collaborative cross model recapitulates human West Nile virus disease outcomes," MBio, vol. 6, no. 3, pp. e00493-e00415, 2015.

[103] S. J. Allen, S. E. Crown, and T. M. Handel, "Chemokine: receptor structure, interactions, and antagonism," Annual Review of Immunology, vol. 25, pp. 787-820, 2007.

[104] M. P. Hosking and T. E. Lane, "The role of chemokines during viral infection of the CNS," PLoS Pathogens, vol. 6, no. 7, Article ID e1000937, 2010.

[105] A. Zlotnik and O. Yoshie, "Chemokines: a new classification system and their role in immunity," Immunity, vol. 12, no. 2, pp. 121-127, 2000.

[106] L. C. Borish and J. W. Steinke, "2. Cytokines and chemokines," Journal of Allergy and Clinical Immunology, vol. 111, no. 2, supplement, pp. S460-S475, 2003.

[107] A. Sulik, A. Kroten, M. Wojtkowska, and E. Oldak, "Increased levels of cytokines in cerebrospinal fluid of children with aseptic meningitis caused by mumps virus and echovirus 30 ," Scandinavian Journal of Immunology, vol. 79, no. 1, pp. 68-72, 2014.

[108] M. S. Bastos, J. G. Coelho-Dos-Reis, D. A. G. Zauli et al., "Divergent cerebrospinal fluid cytokine network induced by non-viral and different viral infections on the central nervous system," BMC Infectious Diseases, vol. 15, no. 1, article 345, 2015.

[109] S.-M. Wang, H.-Y. Lei, and C.-C. Liu, "Cytokine immunopathogenesis of enterovirus 71 brain stem encephalitis," Clinical and Developmental Immunology, vol. 2012, Article ID 876241, 8 pages, 2012.

[110] K. Kothur, L. Wienholt, F. Brilot, and R. C. Dale, "CSF cytokines/chemokines as biomarkers in neuroinflammatory CNS disorders: a systematic review," Cytokine, vol. 77, pp. 227237, 2016.

[111] K. Frei, U. V. Malipiero, T. P. Leist, R. M. Zinkernagel, M. E. Schwab, and A. Fontana, "On the cellular source and function of interleukin 6 produced in the central nervous system in viral diseases," European Journal of Immunology, vol. 19, no. 4, pp. 689-694, 1989.

[112] T. Kishimoto, "Interleukin-6: From basic science to medicine40 Years in immunology," Annual Review of Immunology, vol. 23, pp. 1-21, 2005.

[113] D. M. Durrant, B. P. Daniels, and R. S. Klein, "IL-1R1 signaling regulates CXCL12-mediated $\mathrm{T}$ cell localization and fate within the central nervous system during West Nile Virus encephalitis," The Journal of Immunology, vol. 193, no. 8, pp. 4095-4106, 2014.

[114] E. E. McCandless, Q. Wang, B. Mark Woerner, J. M. Harper, and R. S. Klein, "CXCL12 limits inflammation by localizing mononuclear infiltrates to the perivascular space during experimental autoimmune encephalomyelitis," Journal of Immunology, vol. 177, no. 11, pp. 8053-8064, 2006.

[115] S. Osmanov, C. Pattou, N. Walker et al., "Estimated global distribution and regional spread of HIV-1 genetic subtypes in the year 2000," Journal of Acquired Immune Deficiency Syndromes, vol. 29, no. 2, pp. 184-190, 2002. 
[116] M. Sanmarti, L. Ibanez, S. Huertas et al., "HIV-associated neurocognitive disorders," Journal of Molecular Psychiatry, vol. 2, no. 1, p. 2, 2014.

[117] M. Toborek, Y. W. Lee, G. Flora et al., "Mechanisms of the blood-brain barrier disruption in HIV-1 infection," Cellular and Molecular Neurobiology, vol. 25, no. 1, pp. 181-199, 2005.

[118] N. Chomont, M. El-Far, P. Ancuta et al., "HIV reservoir size and persistence are driven by $\mathrm{T}$ cell survival and homeostatic proliferation," Nature Medicine, vol. 15, no. 8, pp. 893-900, 2009.

[119] T.-W. Chun, L. Carruth, D. Finzi et al., "Quantification of latent tissue reservoirs and total body viral load in HIV-1 infection," Nature, vol. 387, no. 6629, pp. 183-188, 1997.

[120] L. Redel, V. Le Douce, T. Cherrier et al., "HIV-1 regulation of latency in the monocyte-macrophage lineage and in CD4+ T lymphocytes," Journal of Leukocyte Biology, vol. 87, no. 4, pp. 575-588, 2010.

[121] B. F. Keele, E. E. Giorgi, J. F. Salazar-Gonzalez et al., "Identification and characterization of transmitted and early founder virus envelopes in primary HIV-1 infection," Proceedings of the National Academy of Sciences of the United States of America, vol. 105, no. 21, pp. 7552-7557, 2008.

[122] E. A. Eugenin, K. Osiecki, L. Lopez, H. Goldstein, T. M. Calderon, and J. W. Berman, "CCL2/monocyte chemoattractant protein-1 mediates enhanced transmigration of human immunodeficiency virus (HIV)-infected leukocytes across the bloodbrain barrier: a potential mechanism of HIV-CNS invasion and NeuroAIDS," The Journal of Neuroscience, vol. 26, no. 4, pp. 1098-1106, 2006.

[123] C. T. Costiniuk and M.-A. Jenabian, "Cell-to-cell transfer of HIV infection: implications for HIV viral persistence," Journal of General Virology, vol. 95, pp. 2346-2355, 2014.

[124] D. W. Williams, T. M. Calderon, L. Lopez et al., "Mechanisms of HIV entry into the CNS: increased sensitivity of HIV infected CD14+CD16+ monocytes to CCL2 and key roles of CCR2, JAMA, and ALCAM in diapedesis," PLoS ONE, vol. 8, no. 7, Article ID e69270, 2013.

[125] M. Kaul, G. A. Garden, and S. A. Lipton, "Pathways to neuronal injury and apoptosis in HIV-associated dementia," Nature, vol. 410, no. 6831, pp. 988-994, 2001.

[126] D. W. Williams, E. A. Eugenin, T. M. Calderon, and J. W. Berman, "Monocyte maturation, HIV susceptibility, and transmigration across the blood brain barrier are critical in HIV neuropathogenesis," Journal of Leukocyte Biology, vol. 91, no. 3, pp. 401-415, 2012.

[127] K. E. Peterson, S. J. Robertson, J. L. Portis, and B. Chesebro, "Differences in cytokine and chemokine responses during neurological disease induced by polytropic murine retroviruses map to separate regions of the viral envelope gene," Journal of Virology, vol. 75, no. 6, pp. 2848-2856, 2001.

[128] L. Yuan, L. Qiao, F. Wei et al., "Cytokines in CSF correlate with HIV-associated neurocognitive disorders in the post-HAART era in China," Journal of NeuroVirology, vol. 19, no. 2, pp. 144149, 2013.

[129] R. J. Whitley and B. Roizman, "Herpes simplex virus infections," The Lancet, vol. 357, no. 9267, pp. 1513-1518, 2001.

[130] M. F. Kramer, W. J. Cook, F. P. Roth et al., "Latent herpes simplex virus infection of sensory neurons alters neuronal gene expression," Journal of Virology, vol. 77, no. 17, pp. 9533-9541, 2003.
[131] J. Piret and G. Boivin, “Innate immune response during herpes simplex virus encephalitis and development of immunomodulatory strategies," Reviews in Medical Virology, vol. 25, no. 5, pp. 300-319, 2015.

[132] S. F. Mekan, M. Wasay, B. Khelaeni, Z. Saeed, A. Hassan, and M. Sheerani, "Herpes simplex encephalitis: analysis of 68 cases from a tertiary care hospital in Karachi, Pakistan," Journal of the Pakistan Medical Association, vol. 55, no. 4, pp. 146-148, 2005.

[133] T. R. Wuest and D. J. J. Carr, "Dysregulation of CXCR3 signaling due to CXCL10 deficiency impairs the antiviral response to herpes simplex virus 1 infection," The Journal of Immunology, vol. 181, no. 11, pp. 7985-7993, 2008.

[134] M. Baggiolini, "Chemokines and leukocyte traffic," Nature, vol. 392, no. 6676, pp. 565-568, 1998.

[135] M. M. Teixeira, M. C. Vilela, F. M. Soriani, D. H. Rodrigues, and A. L. Teixeira, "Using intravital microscopy to study the role of chemokines during infection and inflammation in the central nervous system," Journal of Neuroimmunology, vol. 224, no. 1-2, pp. 62-65, 2010.

[136] D. J. J. Carr, J. Ash, T. E. Lane, and W. A. Kuziel, "Abnormal immune response of CCR5-deficient mice to ocular infection with herpes simplex virus type 1," Journal of General Virology, vol. 87, part 3, pp. 489-499, 2006.

[137] S. S. Ousman and P. Kubes, "Immune surveillance in the central nervous system," Nature Neuroscience, vol. 15, no. 8, pp. 10961101, 2012.

[138] C. D. Conrady, M. Thapa, T. Wuest, and D. J. J. Carr, "Loss of mandibular lymph node integrity is associated with an increase in sensitivity to HSV-1 infection in CD118-deficient mice," The Journal of Immunology, vol. 182, no. 6, pp. 3678-3687, 2009.

[139] N. Boivin, R. Menasria, D. Gosselin, S. Rivest, and G. Boivin, "Impact of deficiency in CCR2 and CX3CR1 receptors on monocytes trafficking in herpes simplex virus encephalitis," Journal of General Virology, vol. 93, part 6, pp. 1294-1304, 2012.

[140] S. Wickham, B. Lu, J. Ash, and D. J. J. Carr, "Chemokine receptor deficiency is associated with increased chemokine expression in the peripheral and central nervous systems and increased resistance to herpetic encephalitis," Journal of Neuroimmunology, vol. 162, no. 1-2, pp. 51-59, 2005.

[141] A. Rösler, M. Pohl, H.-J. Braune, W. H. Oertel, D. Gemsa, and H. Sprenger, "Time course of chemokines in the cerebrospinal fluid and serum during herpes simplex type 1 encephalitis," Journal of the Neurological Sciences, vol. 157, no. 1, pp. 82-89, 1998.

[142] C. M. Dorobantu, L. Albulescu, C. Harak et al., "Modulation of the host lipid landscape to promote RNA virus replication: the picornavirus encephalomyocarditis virus converges on the pathway used by hepatitis C virus," PLoS Pathogens, vol. 11, no. 9, Article ID e1005185, 2015.

[143] R. T. Johnson, E. L. Buescher, N. G. Rogers, M. J. Funkenbusch, and W. E. Oliu, "Epidemic central nervous system disease of mixed enterovirus etiology: analysis of laboratory investigations," American Journal of Epidemiology, vol. 71, no. 3, pp. 331341, 1960.

[144] H. Rudolph, H. Schroten, and T. Tenenbaum, "Enterovirus infections of the central nervous system in children-an update," The Pediatric Infectious Disease Journal, vol. 35, no. 5, pp. 567-569, 2016.

[145] R. Feuer, C. M. Ruller, N. An et al., "Viral persistence and chronic immunopathology in the adult central nervous system following coxsackievirus infection during the neonatal period," Journal of Virology, vol. 83, no. 18, pp. 9356-9369, 2009. 
[146] M. Sato, M. Hosoya, K. Honzumi et al., "Cytokine and cellular inflammatory sequence in enteroviral meningitis," Pediatrics, vol. 112, no. 5, pp. 1103-1107, 2003.

[147] S.-M. Wang, H.-Y. Lei, C.-K. Yu, J.-R. Wang, I.-J. Su, and C.-C. Liu, "Acute chemokine response in the blood and cerebrospinal fluid of children with enterovirus 71-associated brainstem encephalitis," Journal of Infectious Diseases, vol. 198, no. 7, pp. 1002-1006, 2008.

[148] L. M. Huffman, B. T. Fife, W. S. Begolka, S. D. Miller, and W. J. Karpus, "Central nervous system chemokine expression during Theiler's virus-induced demyelinating disease," Journal of NeuroVirology, vol. 5, no. 6, pp. 635-642, 1999.

[149] J. S. Mackenzie, D. J. Gubler, and L. R. Petersen, "Emerging flaviviruses: the spread and resurgence of Japanese encephalitis, West Nile and dengue viruses," Nature Medicine, vol. 10, supplement 12, pp. S98-S109, 2004.

[150] M. K. Goverdhan, A. B. Kulkarni, A. K. Gupta, C. D. Tupe, and J. J. Rodrigues, "Two-way cross-protection between West Nile and Japanese encephalitis viruses in bonnet macaques," Acta Virologica, vol. 36, no. 3, pp. 277-283, 1992.

[151] A. H. Eldadah and N. Nathanso, "Pathogenesis of west nile virus encephalitis in mice and rats .2. Virus multiplication evolution of immunofluorescence and development of histological lesions in brain," American Journal of Epidemiology, vol. 86, no. 3, p. 776, 1967.

[152] R. B. Tesh, M. Siirin, H. Guzman et al., "Persistent West Nile Virus infection in the golden hamster: studies on its mechanism and possible implications for other flavivirus infections," Journal of Infectious Diseases, vol. 192, no. 2, pp. 287-295, 2005.

[153] M. L. Bunning, R. A. Bowen, C. B. Cropp et al., "Experimental infection of horses with West Nile virus," Emerging Infectious Diseases, vol. 8, no. 4, pp. 380-386, 2002.

[154] N. Charlier, P. Leyssen, E. D. Clercq, and J. Neyts, "Rodent models for the study of therapy against flavivirus infections," Antiviral Research, vol. 63, no. 2, pp. 67-77, 2004.

[155] R. S. Klein, E. Lin, B. Zhang et al., "Neuronal CXCL10 directs CD8+ T-cell recruitment and control of West Nile virus encephalitis," Journal of Virology, vol. 79, no. 17, pp. 11457-11466, 2005.

[156] W. G. Glass, J. K. Lim, R. Cholera, A. G. Pletnev, J.-L. Gao, and P. M. Murphy, "Chemokine receptor CCR5 promotes leukocyte trafficking to the brain and survival in West Nile virus infection," Journal of Experimental Medicine, vol. 202, no. 8, pp. 1087-1098, 2005.

[157] B. Zhang, K. C. Ying, B. Lu, M. S. Diamond, and R. S. Klein, "CXCR3 mediates region-specific antiviral $\mathrm{T}$ cell trafficking within the central nervous system during west nile virus encephalitis," The Journal of Immunology, vol. 180, no. 4, pp. 2641-2649, 2008.

[158] B. Shrestha and M. S. Diamond, "Role of CD8+ T cells in control of West Nile virus infection," Journal of Virology, vol. 78, no. 15, pp. 8312-8321, 2004.

[159] K. Shirato, T. Kimura, T. Mizutani, H. Kariwa, and I. Takashima, "Different chemokine expression in lethal and non-lethal murine West Nile virus infection," Journal of Medical Virology, vol. 74, no. 3, pp. 507-513, 2004.

[160] E. E. McCandless, B. Zhang, M. S. Diamond, and R. S. Klein, "CXCR4 antagonism increases T cell trafficking in the central nervous system and improves survival from West Nile virus encephalitis," Proceedings of the National Academy of Sciences of the United States of America, vol. 105, no. 32, pp. 11270-11275, 2008.

[161] N. A. Prow and D. N. Irani, "The inflammatory cytokine, interleukin-1 beta, mediates loss of astroglial glutamate transport and drives excitotoxic motor neuron injury in the spinal cord during acute viral encephalomyelitis," Journal of Neurochemistry, vol. 105, no. 4, pp. 1276-1286, 2008.

[162] D. M. Durrant, M. L. Robinette, and R. S. Klein, "IL-1R1 is required for dendritic cell-mediated $\mathrm{T}$ cell reactivation within the CNS during west Nile virus encephalitis," The Journal of Experimental Medicine, vol. 210, no. 3, pp. 503-516, 2013.

[163] B. S. Kim, Y.-H. Jin, L. Meng et al., "IL-1 signal affects both protection and pathogenesis of virus-induced chronic CNS demyelinating disease," Journal of Neuroinflammation, vol. 9, article 217, 2012.

[164] H. J. Ramos, M. C. Lanteri, G. Blahnik et al., "IL-1 $\beta$ signaling promotes CNS-intrinsic immune control of West Nile virus infection," PLoS Pathogens, vol. 8, no. 11, Article ID e1003039, 2012.

[165] S. V. Bardina, D. Michlmayr, K. W. Hoffman et al., "Differential roles of chemokines CCL2 and CCL7 in monocytosis and leukocyte migration during West Nile virus infection," Journal of Immunology, vol. 195, no. 9, pp. 4306-4318, 2015.

[166] R. L. Terry, D. R. Getts, C. Deffrasnes, C. van Vreden, I. L. Campbell, and N. J. C. King, "Inflammatory monocytes and the pathogenesis of viral encephalitis," Journal of Neuroinflammation, vol. 9, article 270, 2012.

[167] C.-L. Tsou, W. Peters, Y. Si et al., "Critical roles for CCR2 and MCP-3 in monocyte mobilization from bone marrow and recruitment to inflammatory sites," The Journal of Clinical Investigation, vol. 117, no. 4, pp. 902-909, 2007.

[168] D. Trobaugh and S. Green, "Of mice and men: protective and pathogenic immune responses to west Nile virus infection," Current Tropical Medicine Reports, vol. 2, no. 1, pp. 41-48, 2015.

[169] C. E. Patterson, J. K. Daley, L. A. Echols, T. E. Lane, and G. F. Rall, "Measles virus infection induces chemokine synthesis by neurons," Journal of Immunology, vol. 171, no. 6, pp. 3102-3109, 2003.

[170] T. Asano, K. Ichiki, S. Koizumi et al., "Enhanced expression of cytokines/chemokines in cerebrospinal fluids in mumps meningitis in children," Pediatrics International, vol. 53, no. 2 , pp. 143-146, 2011.

[171] A. Lo Presti, A. Lai, E. Cella, G. Zehender, and M. Ciccozzi, "Chikungunya virus, epidemiology, clinics and phylogenesis: a review," Asian Pacific Journal of Tropical Medicine, vol. 7, no. 12, pp. 925-932, 2014.

[172] S. M. Volk, R. Chen, K. A. Tsetsarkin et al., "Genome-scale phylogenetic analyses of chikungunya virus reveal independent emergences of recent epidemics and various evolutionary rates," Journal of Virology, vol. 84, no. 13, pp. 6497-6504, 2010.

[173] R. S. Nasci, "Movement of chikungunya virus into the Western hemisphere," Emerging Infectious Diseases, vol. 20, no. 8, pp. 1394-1395, 2014.

[174] I. Schuffenecker, I. Iteman, A. Michault et al., "Genome microevolution of chikungunya viruses causing the Indian Ocean outbreak," PLoS Medicine, vol. 3, no. 7, article e263, 2006.

[175] N. H. Chandak, R. S. Kashyap, D. Kabra et al., "Neurological complications of Chikungunya virus infection," Neurology India, vol. 57, no. 2, pp. 177-180, 2009. 
[176] A. M. Powers and C. H. Logue, "Changing patterns of chikunya virus: re-emergence of a zoonotic arbovirus," Journal of General Virology, vol. 88, no. 9, pp. 2363-2377, 2007.

[177] M. Sourisseau, C. Schilte, N. Casartelli et al., "Characterization of reemerging chikungunya virus," PLoS Pathogens, vol. 3, no. 6, article e89, 2007.

[178] R. Priya, I. K. Patro, and M. M. Parida, "TLR3 mediated innate immune response in mice brain following infection with Chikungunya virus," Virus Research, vol. 189, pp. 194-205, 2014.

[179] R. Priya, R. Dhanwani, I. K. Patro, P. V. L. Rao, and M. M. Parida, "Differential regulation of TLR mediated innate immune response of mouse neuronal cells following infection with novel ECSA genotype of Chikungunya virus with and without E1: A226V mutation," Infection, Genetics and Evolution, vol. 20, pp. 396-406, 2013. 


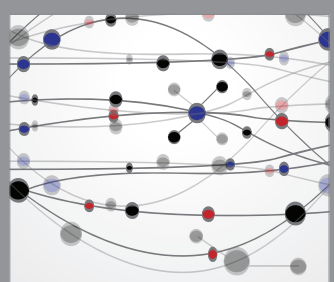

The Scientific World Journal
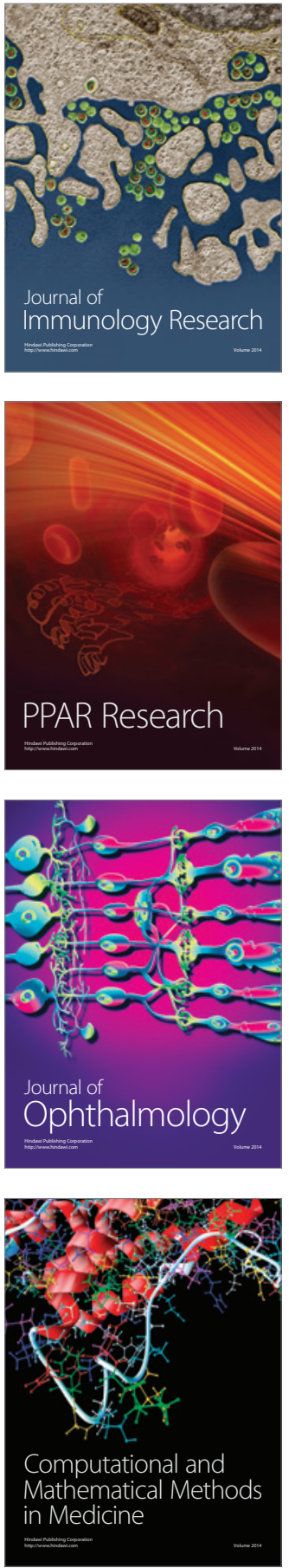

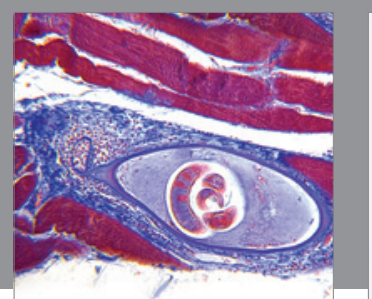

Gastroenterology Research and Practice

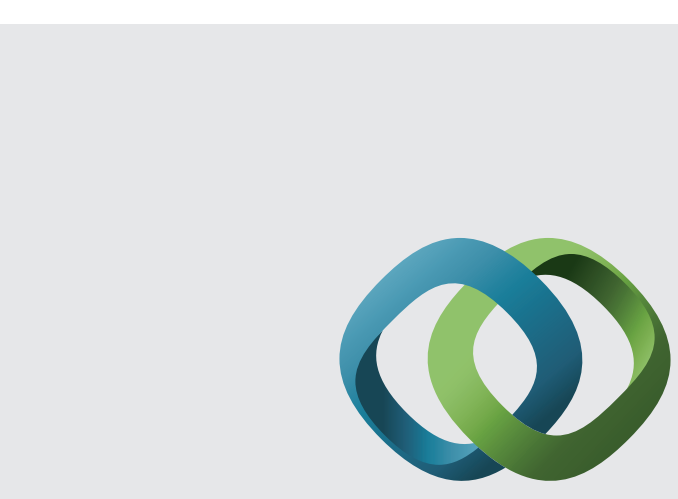

\section{Hindawi}

Submit your manuscripts at

http://www.hindawi.com
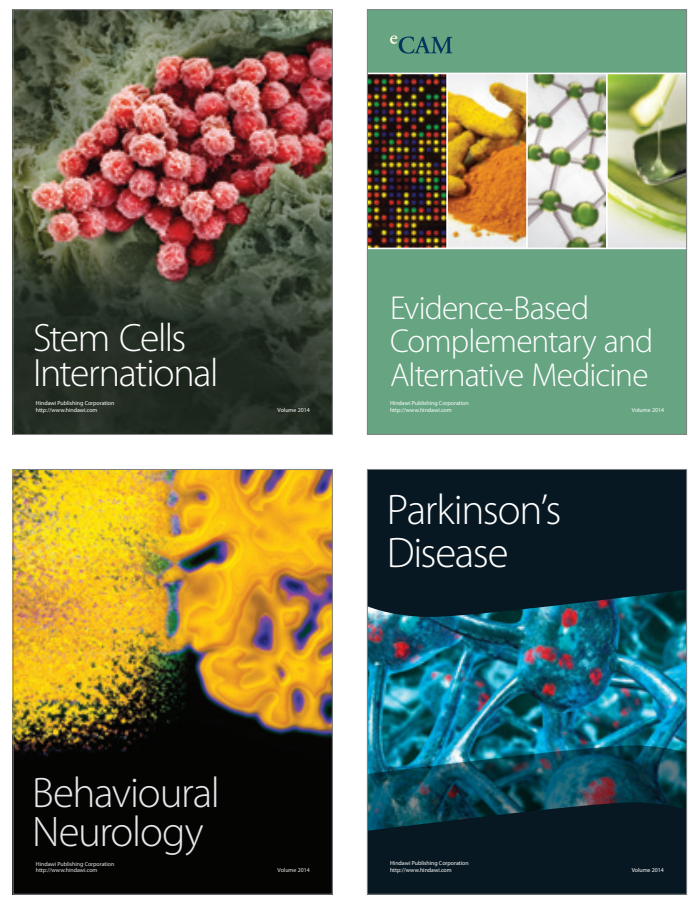


Disease Markers
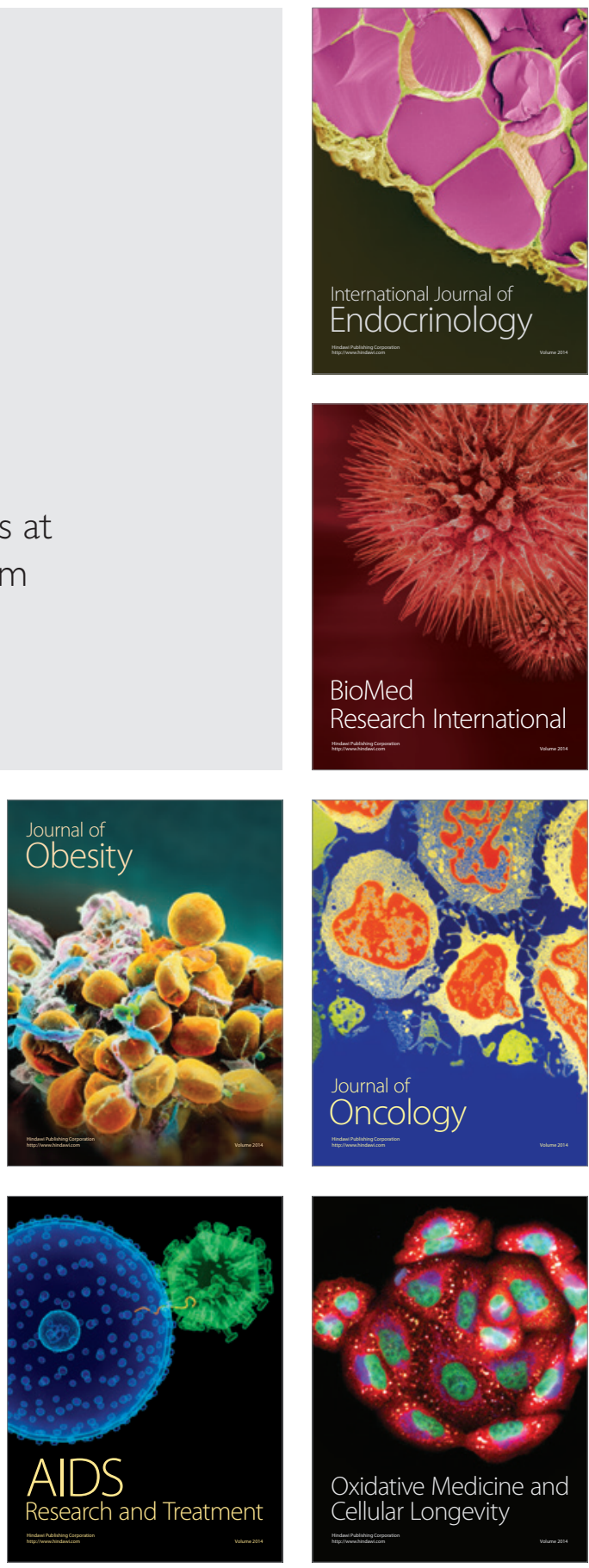